\title{
Neuropathic Pain After Spinal Cord Injury: Challenges and Research Perspectives
}

\author{
Rani Shiao ${ }^{1} \cdot$ Corinne A. Lee-Kubli $^{1}$ (D) \\ Published online: 7 May 2018 \\ (C) The American Society for Experimental NeuroTherapeutics, Inc. 2018
}

\begin{abstract}
Neuropathic pain is a debilitating consequence of spinal cord injury (SCI) that remains difficult to treat because underlying mechanisms are not yet fully understood. In part, this is due to limitations of evaluating neuropathic pain in animal models in general, and SCI rodents in particular. Though pain in patients is primarily spontaneous, with relatively few patients experiencing evoked pains, animal models of SCI pain have primarily relied upon evoked withdrawals. Greater use of operant tasks for evaluation of the affective dimension of pain in rodents is needed, but these tests have their own limitations such that additional studies of the relationship between evoked withdrawals and operant outcomes are recommended. In preclinical SCI models, enhanced reflex withdrawal or pain responses can arise from pathological changes that occur at any point along the sensory neuraxis. Use of quantitative sensory testing for identification of optimal treatment approach may yield improved identification of treatment options and clinical trial design. Additionally, a better understanding of the differences between mechanisms contributing to at- versus below-level neuropathic pain and neuropathic pain versus spasticity may shed insights into novel treatment options. Finally, the role of patient characteristics such as age and sex in pathogenesis of neuropathic SCI pain remains to be addressed.
\end{abstract}

Key Words Operant tests $\cdot$ quantitative sensory testing $\cdot$ animal models $\cdot$ spinal disinhibition $\cdot$ glia.

The hot, burning pain would be replaced at times by severe crushing pressure, by vise-like, pinching sensations, by streams of fire running down the legs into the feet and out the toes, or by a pain produced by the pressure of a knife being buried in the tissue, twisted around rapidly and finally withdrawn all at the same time.

- Description of neuropathic spinal cord injury pain from [1]

Electronic supplementary material The online version of this article (https://doi.org/10.1007/s13311-018-0633-4) contains supplementary material, which is available to authorized users.

Corinne A. Lee-Kubli

cleekubli@salk.edu

1 Molecular Neurobiology Laboratory, The Salk Institute for Biological Studies, 10010 N. Torrey Pines, La Jolla, California 92073, USA

\section{Introduction}

Spinal cord injury (SCI), whether a consequence of falls, vehicular accidents or violence, results in partial or complete interruption of communication from the brain to the regions of the body below the level of injury. Disruption of descending motor tracts results in the most visible symptom of SCI, paralysis. Additional common features of SCI such as pain, spasticity, autonomic dysreflexia, and loss of bladder, bowel, respiratory, and sexual functions further impair quality of life and are treatment areas of high priority for afflicted individuals $[2,3]$. Severe neuropathic pain, in particular, is a strong predictor for reduced quality of life following SCI and is an area of unmet clinical need because it is frequently intractable to conventional treatments [4-7]. Mechanisms underlying SCI pain remain poorly understood, hampering novel therapeutic development. This is in part due to limitations in methods of assessing pain in preclinical rodent models. This 
review will address the relationship between rodent models of SCI pain and the clinical condition, discuss methods of improving preclinical SCI pain research, and identify future research questions that may elucidate novel mechanisms.

\section{Clinical Presentation of SCI Pain}

SCI pain, which develops in approximately two-thirds of patients with SCI $[8,9]$, is broadly categorized as nociceptive (pain arising from nociceptors) or neuropathic (pain arising from damage to the somatosensory nervous system) [10]. Nociceptive pain includes musculoskeletal pain that arises in regions with preserved sensory innervation and can be a consequence of overuse of the arms and back due to wheelchair use. This type of pain is responsive to treatment with nonsteroidal anti-inflammatories (NSAIDs) or opiates. Visceral pain that arises in the abdomen or thorax is also categorized as nociceptive pain, as it can be triggered by food intake or functions of the internal organs, such as defecation [10].

Neuropathic pain, which develops in 53\% of SCI patients [11], is clinically challenging to treat, partially because mechanisms contributing to its development remain elusive. Symptoms can develop either at or below the level of the injury [10]. At-level pain is defined by its presence anywhere within a region spanning one dermatome rostral and three dermatomes caudal to the neurological level of injury (NLI), whereas below-level pain occurs below three dermatomes caudal to the NLI [10]. The NLI is the most caudal dermatome at which normal sensory and motor functions are maintained on both sides of the body; as a result, its relationship to the lesion epicenter is imperfect, particularly in asymmetrical lesions [12]. Because at-level pain arises in regions that are more likely to retain partial sensory function, this type of pain frequently includes allodynia (pain in response to nonpainful stimuli, such as light touch) as well as spontaneous and ongoing pain [13]. In patients with incomplete SCI, below-level pain can also have an allodynic component [10], but a substantial proportion of patients with below-level pain have complete spinal lesions and no sensory function in the painful region [14]. For example, 59\% of patients with at-level pain report pain evoked by touch, compared to only $30 \%$ of patients with below-level pain. Conversely, patients with belowlevel pain are more likely to experience ongoing tingling pins and needles in absence of sensory stimuli (90\%) compared to those with at-level pain (59\%) [13]. Quantitative sensory testing (QST), which evaluates patient responses to specific sensory modalities [15], confirms this trend, finding that pain or dysesthesia in response to brush (59 vs 10\%), cold (52 vs $30 \%$ ), warm (12 vs 10\%), or pinprick (35 vs 25\%) are more common in patients with at-level pain that those with belowlevel pain [13].
Evaluating Pain in Experimental Models of SCI

SCI pain is studied in rodent lesion models including contusions, hemicontusions, hemisections, and complete transections placed anywhere from the cervical to lumbar spinal segments (reviewed in $[16,17]$ ). Nontraumatic SCI models, such as excitotoxic lesions and electrolytic lesions confined to the spinothalamic tract $[18,19]$, have also been developed to study the contribution of specific types of spinal damage to pain generation. There is no consensus as to the best model for use in SCI pain research, though the most commonly used model is the low thoracic (T7-T10) contusion [17]. However, cervical lesions are the most common in the clinical population, occurring in $60 \%$ of SCI patients [20], and belowlevel pain is more likely to arise in patients with severe cervical lesions [9], potentially because these types of lesions disrupt a greater proportion of ascending and descending tracts than lower level injuries. Therefore, recent interest has emerged in modeling SCI pain following cervical lesions $[21,22]$, though these are limited to hemi-lesions due to animal husbandry considerations. Overall, pain can develop in patients with a variety of lesion severities and localizations, so it may be prudent to continue to study pain mechanisms in a variety of lesion models, looking for commonalities. This is particularly important because the best therapeutic options will work against pain in a variety of lesion types.

A majority of preclinical studies of SCI pain have evaluated evoked withdrawal behavior, primarily in response to touch and heat, in the hindpaws following a low thoracic moderate contusion that is associated with partial recovery of locomotor function (for a detailed breakdown, see [17]). However, as the field of pain research is becoming increasingly aware, evoked withdrawals are not representative of the complex human pain experience, and focus on these measures may be one of the reasons that so many targets identified preclinically fail to make it to clinical use [23]. Concern over use of evoked withdrawals is exacerbated in the case of SCI, which can cause direct impairment to pain transmission pathways both below and at the level of injury $[17,24,25]$. Indeed, hindpaw withdrawal behaviors persist even following complete spinal transection [26-28], sometimes with reduced thresholds, demonstrating that these responses do not depend upon conscious pain perception. Enhanced evoked hindlimb withdrawal behaviors in SCI rodents have been proposed to be a symptom of spasticity rather than pain [24]. However, enhanced hindlimb withdrawal behavior can occur in the absence of stretch hyperreflexia indicative of spasticity [25], such that the relationship between hindlimb responses and spasticity remains unclear. Finally, clinical neuropathic SCI pain predominantly presents as spontaneous, ongoing pain, with evoked pain present in only a subset of patients, as described above [13]. Therefore, in pain research in general and SCI research in particular, it is increasingly important that pain measures 
include an emotional-affective dimension and evaluate spontaneous ongoing pain.

\section{Evaluating Conscious Perception of Pain in SCI Models}

Many studies have sought to incorporate a conscious element by recording only withdrawals accompanied by brainstem responses such as turning toward the stimulus, or paying attention to or licking the stimulated paw [17, 24, 29]. Though this is an improvement over measuring only evoked withdrawals, it has been suggested that cautious interpretation of results is warranted because even brainstem responses may reflect a state of curiosity toward an unexpected noise or movement associated with reflexive withdrawal [17]. Even so, brainstem responses are not necessarily indicative of conscious pain perception as decerebrate rats can also exhibit responses to innocuous and noxious sensory stimuli [30-32]. To our knowledge, no published study has conducted operant testing targeting the hindlimbs in a cohort of SCI rats that exhibited brainstem responses to below-level stimuli. Therefore, it remains possible that brainstem responses suffice to identify pain responses. Nevertheless, a stronger approach to SCI pain research will require more consistent use of operant testing, both to confirm presence of pain and treatment efficacy in SCI pain models.

Operant tasks explore the emotional-affective dimension of pain by evaluating whether a rodent is motivated to escape a noxious stimulus (place-escape avoidance paradigm (PEAP) $[33,34]$ and the Mechanical Conflict Avoidance System [35]) or spend time in an environment is associated with pain relief (conditioned place preference (CPP) [36]). However, to date, very few published SCI pain studies have incorporated operant tasks in their research [24, 37-41].

PEAP (Fig. 1a) pits the natural desire of rodents to be in the dark against pain experienced when probed with a stimulus that evokes a withdrawal response [33]. Rodents that are allowed to move freely between a dark and light chamber will typically spend a greater amount of time in the dark. However, when the dark chamber is paired with a painful stimulus, rodents are driven to spend more time in the light [33] (Fig. 1b). PEAP has shown that enhanced below-level withdrawal to tactile stimuli in SCI rats is not aversive, as von Frey stimulation of the hindpaws does not lead to increased escape from the stimulus-paired chamber [24]. In contrast, enhanced atlevel response to von Frey stimulation is associated with increased escape from von Frey stimulation within the region of at-level hypersensitivity [24, 37]. PEAP has also been used to demonstrate pharmacological efficacy of a compound that reduces microglial activation and tissue damage at the lesion epicenter against at-level von Frey stimulation [41].

Though one advantage of PEAP testing is the ability to target specific painful sites for testing, this is also a drawback, in that it requires experimenter-driven stimulus administration at regular intervals, which could introduce error or unintentional biasing of results. An alternate version of the task avoids this problem by warming or cooling the entire floor in the dark side of the chamber. This variant of PEAP has shown that rats with T13 hemisection have reduced sensitivity to noxious heat [39], but those with a spinal stenosis show increased sensitivity to cold and heat [43]. However, this too can be an imperfect approach as only the paws are contact with the stimulus surface, precluding evaluation of at-level pain in the flanks. Rodents could also potentially escape the noxious stimulus by lifting painful limbs off the surface.

The Mechanical Conflict Avoidance System evaluates the willingness of rodents to cross mechanically unpleasant flooring to escape a brightly lit chamber (Fig. 1c). Neuropathic pain due to chronic constriction nerve injury results in increased latency to cross a field of sharp metal spikes relative to uninjured controls, which can be reversed by analgesics [35]. In a rodent model of T12 hemicontusion, latency to cross was reduced by viral overexpression of IL-10 that also attenuated hindpaw mechanical withdrawal responses relative to untreated SCI rats [40]. However, latencies to cross for sham and naïve animals were not reported, so it is unclear whether this test indicated the presence of mechanically evoked pain in this cohort. Because the spikes only come into contact with the fore- and hindpaws, this test will likely not be useful for identifying the presence of at-level flank hypersensitivity and may yield unreliable results in rats that have lost sensory function in the hindlimbs and therefore experience less overall discomfort while crossing. Additional data are required to draw conclusions as to the utility of this test for identifying SCI pain.

CPP testing measures the preference of a rodent to spend time in an environment it associates with pain relief (Fig. 1d). Like PEAP, the CPP apparatus consists of two connected chambers. These are either neutrally lit with distinctive patterning of floors and walls or one chamber is dark whereas the other is well lit. During conditioning sessions, each rodent is confined to one chamber at a time, either after administration of vehicle (dark chamber) or a drug predicted to alleviate neuropathic pain (well-lit chamber) [36, 44, 45]. On a subsequent testing session, the subject is allowed to roam freely between chambers and if greater time is spent in the drug-paired chamber, the pharmacological agent is concluded to have had painrelieving effects (Fig. 1e). Delivery of a drug that reduces below-level spontaneous nociceptor activity and enhanced hindlimb withdrawal leads to CPP for the drug-paired chamber in SCI rats [38, 42]. CPP has also been shown in contused rats in response to morphine administration [46], but this could reflect addiction as CPP can be confounded when testing drugs that have mood-altering effects such as opioids and anti-depressants. Increased use of CPP may improve the quality of candidates advanced to clinical testing, but one limitation is that CPP cannot determine whether pain relief is experienced at- or below-level, which may not allow for identification of mechanisms distinct to these types of SCI pain. 

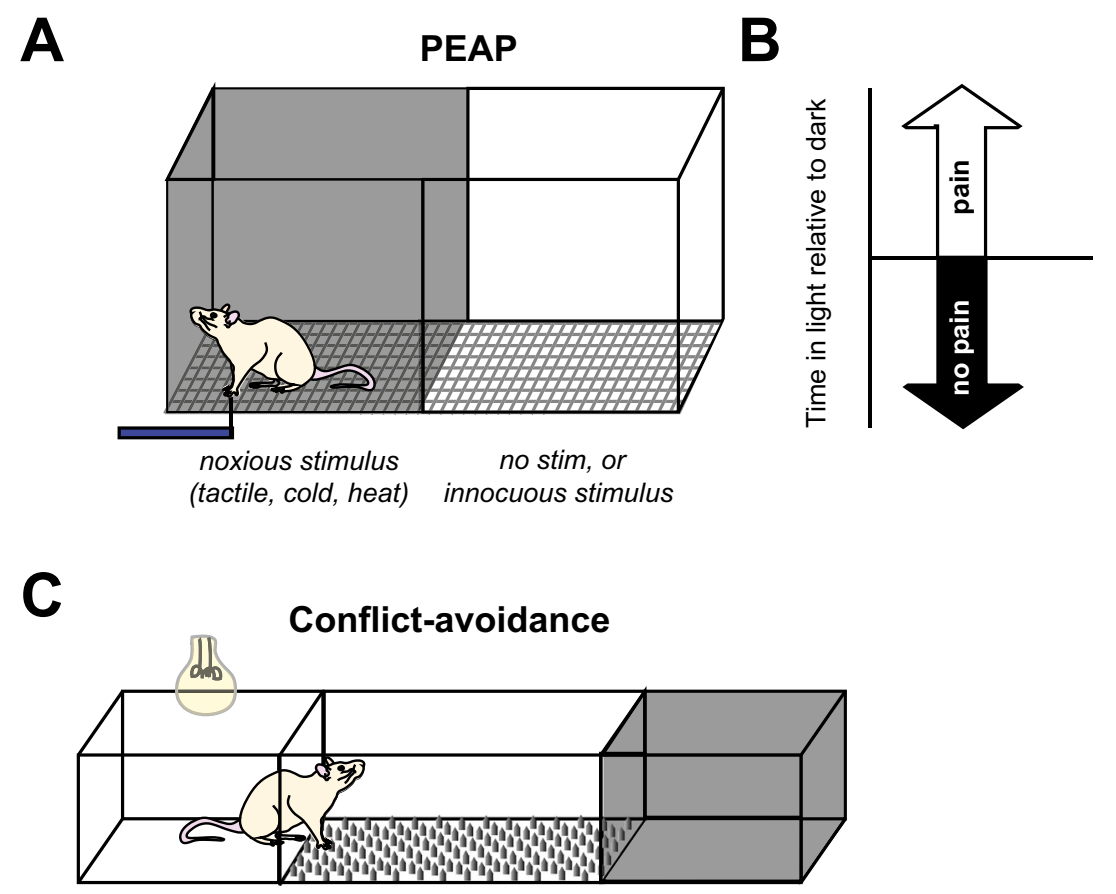

spiked floor
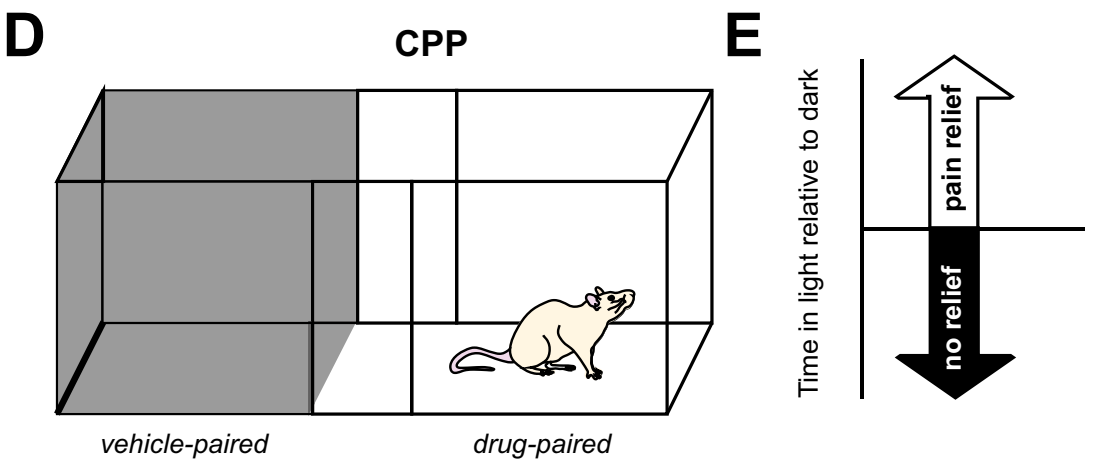

Fig. 1 Operant conditioning tests for evaluation of SCI pain. (A) Placeescape avoidance paradigm (PEAP) pits aversion to light against aversion to a putatively noxious stimulus such as tactile, cold, or heat. In this test, the painful stimulus is presented in (for mechanical stimuli) or makes up the flooring of (for thermal stimuli) only the dark side of the chamber, whereas in the light chamber the stimulus is applied to a potentially nonpainful body region or not at all. (B) Increased time spent in the light side of the chamber is indicative of aversion to the sensory stimulus, suggesting that the rat perceived it as being painful [33]. (C) In the Mechanical Conflict Avoidance System, a light chamber is connected to a dark chamber by noxious flooring consisting of spikes that can be raised to different heights. When the light is turned on, the rat crosses the floor to

The utility of operant tasks could be impeded by reduced exploratory behavior in rodents with SCI [41, 47] and can only be used a limited number of times in individual rats [24], limiting the number of time points and manipulations that can be evaluated in a single cohort. Underlying anxiety and depression, present in patients and rodent models of SCI [48-51], could additionally complicate use of operant testing in rodent models of SCI pain. Finally, though these tests seek reach the dark chamber. Rats with pain exhibit a longer latency to exit the light chamber and begin crossing the noxious flooring [35]. (D) Conditioned place preference (CPP) testing can also use a light/dark chamber setup [42], or two neutrally lit chambers with distinctive flooring and walls [36]. In conditioning trials, the dark side of the chamber is paired with vehicle administration, whereas the light side of the chamber is paired with administration of a drug that may alleviate pain. Chamber preference is evaluated during a subsequent session when the drug is not administered. (E) Increased time spent in the light side of the chamber indicates that the subject experienced pain relief in response to drug administration

to identify whether a stimulus is aversive (PEAP and conflict avoidance) or if a drug increases overall well-being (CPP), they do not necessarily implicate pain as the only driving force, particularly in SCI. For example, hypertensive or spastic episodes in response to hindlimb stimulation following complete SCI could cause rodents to avoid a stimulus-paired environment. Likewise, reduction of hypertension due to autonomic dysreflexia could cause CPP. Therefore, a more 
thorough understanding the relationship between evoked withdrawal responses and behaviors in operant tasks is critical for improving the translational relevance of preclinical SCI pain research.

\section{Evaluating Spontaneous Pain in Rodent Models of SCI}

Spontaneous pain is commonly described in the clinic as the experience of burning, shooting, or stabbing pain at or below the level of injury in the absence of a consciously perceived stimulus [52]. One of the challenges of evaluating spontaneous pain in rodents is that they cannot self-report their experience of pain. Therefore, proxy measurements are necessary. Pain alleviation in CPP arguably reflects alleviation of ongoing spontaneous pain [36]. Additional efforts to identify ongoing, spontaneous pain in SCI models include evaluating atlevel spontaneous paw lifting behaviors and quantifying changes to exploratory behavior, both of which are reversed by administration of gabapentin $[37,47]$, suggesting that they are due to ongoing neuropathic pain.

The grimace scale, which quantifies the presence of stereotyped facial responses (grimaces) to pain [53], has also been used to identify ongoing discomfort in SCI models [54, 55]. Rats with a C5 hemicontusion have higher grimace scale scores than sham rats 5 weeks postinjury, and grimacing increases following stimulation of the contralateral hindpaw with acetone [55]. A study of mice with thoracic contusion found increased grimace scores only in the first 3 weeks after injury [54]. It is not clear whether the resolution of grimacing indicates that the experience of spontaneous pain is resolved, and therefore, use of grimace scale for evaluation of pain in chronic animals may be limited if rodents adjust their facial expressions in response to chronic pain. Long-term evaluation of grimace scale in conjunction with operant testing may lend clarity to this issue. However, aspects of grimacing behavior also develop due to illness [53], so it is possible that rodents exhibit grimacing behavior in response to distressing, but not necessarily painful, SCI-related events such as spasticity, paresthesias, numbness, loss of locomotor function, or autonomic dysreflexia. Future studies are needed to clarify these potential confounds.

\section{Evoked Withdrawal Testing in Models of SCI}

In addition to operant testing described above, a variety of stimuli have been used to evaluate evoked responses either in the hindlimbs below the lesion level, the flank at level, and the forepaws at or above the lesion level, depending on the injury model. Tactile, heat, and cold stimuli are the most commonly used in SCI pain research. Despite the uncertainty as to what evoked responses represent, particularly below the lesion level, interest in relating QST profiles in human patients with different pharmacological approaches to pain relief
[56-58] make it increasingly important to study circuitry and mechanisms contributing to different pain modalities. Furthermore, the complexities of operant testing make it an unwieldy approach for screening drugs that may alleviate pain, such that continued evaluation of evoked behaviors may be a necessary component of pain research. Therefore, better defining the relationship between evoked withdrawals and operant testing may be instructive.

\section{Mechanical Responses}

A majority of studies of SCI pain have evaluated hindlimb withdrawal from von Frey stimulation following low thoracic contusion either alone or in combination with evaluation of brainstem responses [17]. The same filaments are also used for QST in patients, which has confirmed the presence of allodynia or dysesthesia to von Frey stimulation in regions of both at- and below-level pain [59]. Reduced tactile withdrawal thresholds have been reported in the hindlimbs following low thoracic contusion, compression, hemisection, and transection [24, 28, 60, 61]. At-level sensitivity develops on the flank after low thoracic contusion, compression, or hemisection and in the forepaws after high thoracic transection or compression and cervical hemicontusion [21, 24, 37, $60,61]$. Above-level forepaw tactile allodynia has also been described following low thoracic contusion and hemisection $[60,62]$, though not following complete transections of low thoracic regions $[28,37,63]$. The presence of above-level allodynia in dermatomes far remote from the lesion epicenter are difficult to reconcile with the current ISCIP definition of SCI pain, which does not include the category of above-level pain described in older clinical description of SCI pain [10]. Though above-level neuropathic pain can develop in patients with SCI, it is considered to be a consequence of complex regional pain syndrome (CRPS) or nerve entrapment such as carpal tunnel syndrome, rather than as a consequence of SCI per se [64]. It is unclear whether SCI rodents develop similar syndromes as a consequence of long-term postural adjustment.

Girdle testing consists of evaluating responses to mechanical stimulation of the flanks in order to capture the zone of atlevel pain $[24,60]$. Unlike in human patients, in which at-level pain is described to extend from one segment rostral to three segments caudal [10], girdle testing in rodents following thoracic contusion or complete transection reveals a pattern of trunk sensitivity that extends from the dermatomes corresponding to the injury level to several dermatomes rostral $[24,28,60]$. One possible explanation for this difference in SCI pain pattern is that a single spinal segment in humans ranges from 15 to $20 \mathrm{~mm}$ long in the cervical-thoracic spinal cord, with a total spinal cord length of $\sim 450 \mathrm{~mm}$ [65], whereas the entire length of the adult rat spinal cord is only $120 \mathrm{~mm}$ [66]. Therefore, the slightly rostral extension of 
hypersensitivity could be due to spread of inflammatory factors from the lesion site [67] that could affect a greater number of dermatomes in the rat compared to the human. Nevertheless, this does not explain why at-level pain does not extend caudally relative to the lesion site. Another potential explanation is that the lesion level is identified in rodents as the segment at which the lesion was inflicted, whereas in humans the NLI reflects the highest dermatome at which sensory and motor function are normal [12]. It is possible that the NLI in a rodent would be some spinal levels rostral from the lesion epicenter. However, QST in human patients has also revealed abnormal patterns of tactile sensitivity and dysesthesia in dermatomes rostral to the NLI [68]. Therefore, increased mechanical sensitivity in regions above the lesion level in rats could reflect a similar type of dysesthesia rather than pain. As nonpainful sensations are correlated with pain and can also interfere with quality of life [69], the relevance of evaluating dysesthesia rather than pain should not be discounted. The need to restrain the animal during girdle testing can limit reliability of this test as restraint has some animals develop a hypervigilance that results in responding to every applied stimulus in a subset of uninjured rats [24].

Reliance on reduced tactile withdrawal thresholds to indicate below-level pain following incomplete SCI has been largely questioned due to a report that below-level stimulation of the hindpaws is not aversive in PEAP testing, despite reduced paw withdrawal thresholds in those rats [24]. However, lesion severities may differ across labs and across studies, such that a single cohort of SCI rats may not be representative of all contusion lesions. For example, the rats in the Baastrup et al. [24] study did not have enhanced brainstem responses to hindlimb stimulation, whereas contused rats in other studies do $[29,70]$. Therefore, additional studies on the relationship between below-level tactile withdrawal responses and operant tasks are warranted. In contrast, tactile stimulation of the torso following thoracic contusion and the forepaws following T3 complete transection are aversive in PEAP indicating that atlevel responses to von Frey stimulation have an aversive component $[24,37,41]$.

\section{Heat Response}

A great number of studies have evaluated hindpaw and/or forepaw withdrawal to heat stimuli and reported decreased withdrawal thresholds indicative of greater sensitivity to heat stimuli, or thermal hyperalgesia $[17,71]$. Thermal withdrawal latency is evaluated most frequently using the Hargreaves apparatus, which applies a radiant heat source to the plantar surface of the paw through a glass surface [72]. This is analogous to the portion of the QST that evaluates heat detection and pain thresholds, though the heat stimulus is delivered differently [73]. Hargreaves testing allows for independent testing of all paws individually and thus provides a great deal of specificity as to which limbs have reduced thermal withdrawal thresholds. In contrast, hot plate testing, which is occasionally used in SCI pain research [74], stimulates all four limbs and the tail at once, thereby potentially confounding the response in cases in which rodents have lost sensory function below the lesion level.

Due to the relative infrequency of thermal sensitivity in SCI patients ( $\sim 10 \%$ [59]) coupled with the high prevalence of thermal hyperalgesia reported in rodent models of SCI pain, cautious interpretation of these results is recommended [17]. Indeed, one study observed reduced conscious escape behavior in response to thermal stimuli applied to the hindlimbs of restrained rats with $\mathrm{T} 9$ contusion [25] that commonly display hindlimb thermal sensitivity [75-77]. Additionally, operant testing in a model of T13 lateral hemisection found that escape from 44 and $47^{\circ} \mathrm{C}$ platform is reduced in SCI rats relative to their baseline [39] in contrast to findings of bilateral hind- and fore-limb heat sensitivity reported in another study of this lesion model [60]. However, in both Van Gorp et al. [25] and Vierck et al. [39], hindpaw withdrawal latencies were not reported, so differences in outcomes could have to do with differences between strains or surgical techniques used across different labs. Nevertheless, these findings underscore the need to conduct further operant testing alongside evoked thermal withdrawals to determine the extent to which enhanced evoked withdrawals are indicative of altered thermal sensitivity following SCI.

\section{Cold Response}

Cold allodynia is reported by a subset of patients with SCI pain [73], and cold temperatures enhance the incidence of spontaneous pain sensations [78]. Hindlimb cold allodynia and hyperalgesia have been reported in models of ischemia, contusion, hemisection, and complete transection SCI [28, 79-82], while at-level cold allodynia has also been reported following ischemic SCI [83], thoracic contusion [24], compression, and complete transection [28, 37].

A majority of cold response testing has used acetone or ethyl chloride [24, 28, 79-82], which produces a sensation of cold that cannot be quantified, may be dependent on the skin temperature of the subject being tested, and emits a chemical or olfactory stimulus that could cause a response independent from the change in skin temperature [84]. Recent studies have evaluated at-level cold allodynia in SCI rats using a Peltier device that can generate calibrated cold temperatures on its face $[37,83]$. Peltier devices are similar to those used for QST in patients [73] and provide an advantage in that the temperature needed to elicit a response can be determined. Cold sensitivity in SCI rats has also been studied using PEAP, pitting a dark chamber with a floor cooled to $10{ }^{\circ} \mathrm{C}$ against a neutral flooring in a brightly lit compartment. In this 
case, $60 \%$ of rodents with chronic spinal stenosis gradually showed increased escape from the cold flooring [43]. Additional use of this operant test in models of traumatic $\mathrm{SCI}$ is needed to determine whether cold responses to acetone and contact with a Peltier probe are indicative of pain in response to cold stimulation.

\section{Mechanisms of Neuropathic SCI Pain}

A number of mechanisms have been proposed for SCI pain, many of them recently reviewed $[67,85]$. Because the majority of studies have relied primarily on hindlimb evoked withdrawal responses that may not be directly linked to neuropathic pain, this section will focus on selected mechanisms of SCI pain that have been demonstrated in both at- and below-level pain responses or confirmed using operant conditioning. However, mechanisms that contribute solely to below-level withdrawal responses may be relevant to development of spasticity and/or autonomic dysreflexia and merit further consideration. Additionally, up to $50 \%$ of patients with complete SCI have fMRI activation of the somatosensory cortex in response to below-level brush stimulation despite absence of conscious perception of the stimulus [86], indicating that unperceived below-level sensory inputs could contribute to the ongoing below-level pain. Therefore, neuropathic SCI pain can arise as a consequence of altered sensory processing at any point along the path from peripheral sensation to conscious perception either at or below the level of injury.

\section{Peripheral Mechanisms}

Even though SCI primarily results in damage to the tissue of the spinal cord, several studies have documented changes in peripheral nociceptor function and spontaneous activity at all levels of the neuraxis, including in cervical DRG following a thoracic lesion [42, 62, 87, 88]. Elevated spontaneous activity is associated with increased vocalization responses to at-level stimulation [87]. Increased excitability of at-level nociceptors has been ascribed to reduced membrane expression of the Kv3.4 potassium channel [88], whereas spontaneous activity of below-level nociceptors has been linked to increased expression of Nav1.8 sodium channels [42]. Anti-sense knockdown of Nav1.8 or treatment with retigabine, a KCNQ potassium channel activator, reduces spontaneous activity and reverses below-level decreases in mechanical and thermal withdrawal thresholds, implicating spontaneous nociceptor activity as a mechanism contributing to below-level evoked withdrawal responses [38, 42]. Importantly, retigabine also induces CPP in SCI rats suggesting that it improves ongoing pain [42], though it is unclear whether this is due exclusively to effects on hindlimb innervating DRG neurons.
DRG neurons communicate extensively with the satellite cells that ensheath them, and activation of DRG soma leads to ATP release that activates $\mathrm{P} 2 \mathrm{X} 7$ receptors on satellite cells [89]. Conversely, activated satellite cells release neuromodulatory compounds such as tumor necrosis factor alpha (TNF $\alpha$ ) that can influence excitability of DRG neurons [90]. Satellite cells become reactive in DRG from sensory regions innervating the zone of at-level SCI pain [37]. Additionally, reactive satellite cells express more connexin43, a gap junction protein that mediates communication between adjacent satellite cells and is associated with the development of neuropathic pain in other pain models [91]. Administration of connexin-43 blocking peptides acutely reverses enhanced at-level paw withdrawal behaviors, though this could also have been through direct action on glial cells in the spinal cord [37].

In addition to promoting spontaneous activity, SCI leads to an enhanced growth state of nociceptive neurons isolated from at- and below-level DRG [87]. Increased nociceptor sprouting has been observed in the dorsal horns both at [37, 92] and below [93-96] the level of SCI, as well as throughout the neuraxis [97]. The latter may contribute to the development of autonomic dysreflexia, as overexpression of Sema3a reduces CGRP sprouting and hypertension due to colonic distension [98]. Autonomic dysreflexia and neuropathic pain are frequently comorbid [99] and could share mechanisms in common, as has been recently reviewed [100]. Nevertheless, expanded terminal arbors of spontaneously active nociceptive neurons could plausibly generate a wide range of spontaneous pain experiences.

\section{Spinal Mechanisms}

Many pathological changes take place within the spinal cord in response to SCI, and some of these mechanisms may contribute to the development of neuropathic pain. Potential paingenerating mechanisms include reactive gliosis, spinal disinhibition, and spinal hyperexcitability.

$\mathrm{SCI}$ causes persistent changes to microglia and astrocytes both in close proximity to the lesion epicenter and in regions far remote $[62,101,102]$. Activated microglia are found in dermatomes innervating the hindpaws following low thoracic contusions $[76,102]$ and in the cervical spinal cord innervating the forepaws following T3 complete transection [37]. Reactive astrocytes are likewise observed both at and below the lesion level [37, 62, 101, 103] (Fig. 2), though not in all studies of SCI pain [102]. Indeed expression of glial fibrillary acidic protein (GFAP) and astrocyte-associated genes, such as aquaporin 4, is higher in SCI rats with reduced below-level mechanical paw withdrawal thresholds compared to SCI rats with normal sensitivity [101]. Intrathecal treatment with minocycline, which reduces the number of activated microglia (among other off-target effects described in [107]), reverses 


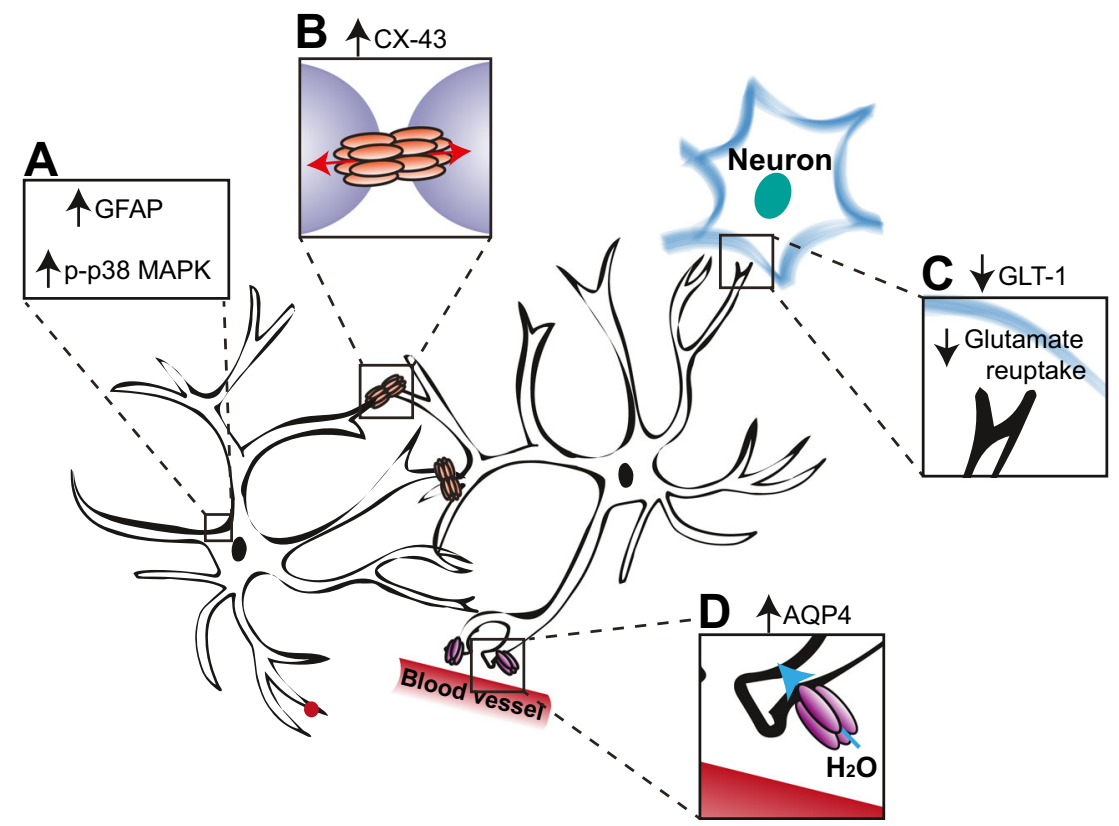

Fig. 2 Reactive astrogliosis contributes to SCI pain. (A) Astrocytes at and below the lesion level upregulate expression of GFAP and p-p38 MAPK, indicators of reactive gliosis [37, 41, 62, 101, 103, 104]. (B) Concomitant increases in the astrocyte-specific gap junction protein, connexin-43 (CX43), could increase connectivity between adjacent astrocytes [37]. (C) Reduced expression of glutamate transporter, GLT-1 [105], would be

hindlimb hypersensitivity and spontaneous and evoked activity in lumbar dorsal horn neurons [76]. Reactive astrocytes are reduced by viral overexpression of interleukin-10 (IL-10) that alleviates measures of evoked hindlimb hypersensitivity and reduces latency to cross a noxious floor in the Mechanical Conflict Avoidance System [40]. Likewise, global or astrocyte-specific deletion of the truncated form of the tropomyosin-related kinase B (TrkB.T1) brain-derived neurotrophic factor (BDNF) receptor results in reduced astrocyte proliferation coupled with partial improvement in hindlimb withdrawal threshold following thoracic contusion SCI [108, 109], an effect that was replicated by cell cycle inhibition even in mice with established hindlimb sensitivity [54]. Pharmacological inhibition of p38 MAPK, expressed in both astrocytes and microglia, reduces at-level brainstem responses to stimulation [104] and avoidance of flank stimulation in PEAP [41]. Inhibition of connexin-43, a gap junction protein predominantly expressed by astrocytes, alleviates at-level tactile hypersensitivity [37], whereas reactive astrocytes and below-level hypersensitivity are attenuated in connexin-43 knockout mice [110]. At-level thermal hyperalgesia following C5 hemicontusion is associated with increased GFAP and concomitant reduction in expression of the astrocyte glutamate transporter (GLT1) in the dorsal horn [105]. GLT1 is the transporter through which astrocytes take up glutamate from the synaptic cleft, so reduced expression could lead to increased excitation within the dorsal horn. Viral overexpression of GLT1 in astrocytes reverses thermal sensitivity in this expected to lead to decreased reuptake of glutamate. (D) Increased upregulation of aquaporin-4 (AQP4) is observed for up to 9 months, but only in rats that develop below-level hypersensitivity [101]. AQP4 is a water transport channel predominantly found in astrocytic foot processes that regulate the blood-brain barrier and may mediate pain behavior by causing astrocyte swelling that results in glutamate release [106]

model [111]. Therefore, there are several lines of evidence that both astrocyte- and microglia-specific mechanisms contribute to pathogenesis of neuropathic pain following SCI.

Spinal disinhibition due to reduced local GABAergic inhibition can also contribute to SCI pain. At-level allodynia following thoracic contusion is associated with reduced $\mathrm{GABA}_{\mathrm{A}}$ receptor-mediated inhibitory function in dorsal horn neurons [112]. This could be due to direct loss of GABAergic inhibitory interneurons or GABA synthesizing enzymes, as has been observed in the lumbar spinal cord following thoracic contusion $[113,114]$ or reduced dorsal horn expression of the potassium-chloride cotransporter $(\mathrm{KCC} 2)$ that maintains the inhibitory capacity of $\mathrm{GABA}_{\mathrm{A}}$ receptors by keeping the intraneuronal chloride concentration low [115] (Fig. 3). GABAergic inhibition is important for gating of sensory stimuli, and loss of inhibition results in hypersensitivity to innocuous stimuli [119].

Below-level pain can result in part from loss of descending fiber tracts that exert tonic inhibitory control of sensory circuitry, such as the raphespinal and cerulospinal projections [120]. However, changes to descending fiber tracts due to injury may have different effects on neuropathic pain and sensory responses at versus below the injury level. For example, serotonin fibers sprout extensively above a spinal cord lesion [61], but are reduced below a T13 hemisection [61, 121]. Ablation of raphespinal projections alleviates at-level allodynia in SCI rats [122], whereas transplantation of serotonin secreting cells alleviates below-level reflex sensitivity 


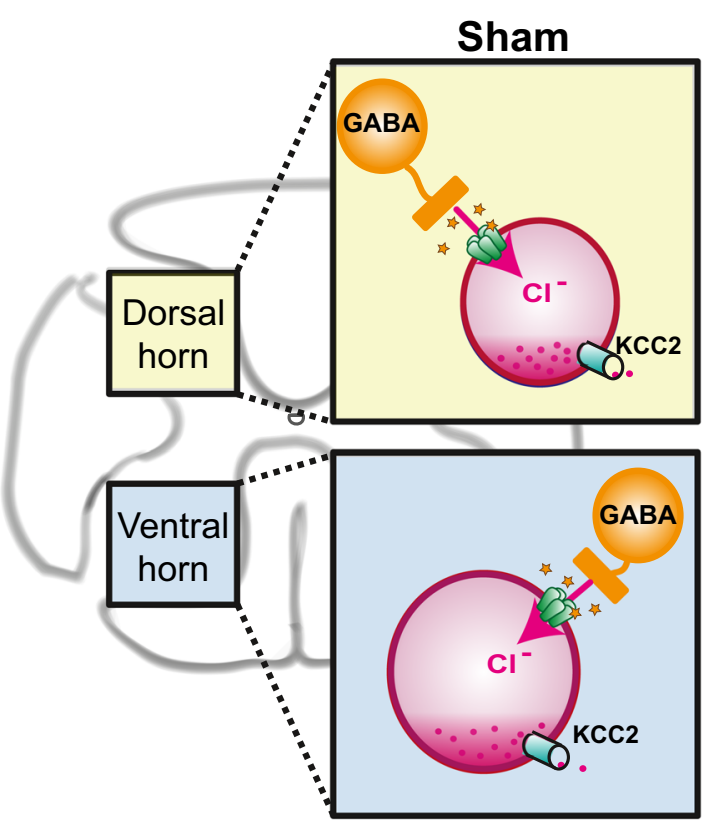

Fig. $3 \mathrm{KCC} 2$ downregulation in the dorsal versus ventral spinal cord has different behavioral outcomes. Under normal conditions, expression of $\mathrm{KCC} 2$ on dorsal horn and motor neurons maintains the neuronal chloride gradient such that activation of ionotropic $\mathrm{GABA}_{\mathrm{A}}$ receptors results in neuronal inhibition (Sham). Reduction or loss of KCC2 expression leads to a build-up of intraneuronal chloride that reduces the inhibitory potential of $\mathrm{GABA}_{\mathrm{A}}$ receptors [116]. Selective loss of KCC2 in dorsal horn

following T13 hemisection [123]. Increased serotonin may mediate at-level pain through activation of 5-HT3 receptors, a ligand-gated cation channel serotonin receptor found on spinal dorsal horn neurons and central terminals of primary afferents $[124,125]$, as treatment with a 5-HT3 receptor antagonist, odansetron, alleviates at-level pain responses [122, 126]. In contrast, 5-HT1 A and 5-HT3 receptor agonists reduce hyperexcitability of below-level spinal neurons from SCI rats [127]. Interestingly, $40 \%$ of serotonin-expressing raphespinal projections co-express substance $\mathrm{P}$ [128], and most co-express glutamate [129], such that altered serotonergic fiber distribution could contribute to sensory changes through both serotonergic and non-serotonergic mechanisms. Taken together, these results suggest that spinal mechanisms contributing to at- and below-level reflex sensitivity may be divergent.

\section{Supraspinal Mechanisms}

SCI in both humans and rodent models is associated with reorganization along the neuraxis as a consequence of deafferentation of different regions (reviewed in [130]). In particular, the somatosensory cortex can reorganize after injury, such that representations of uninjured regions expand into territories that have lost their input [131]. In patients with complete SCI, neuropathic pain correlates with the magnitude of reorganization observed in the primary somatosensory cortex [132]. However, a more recent study

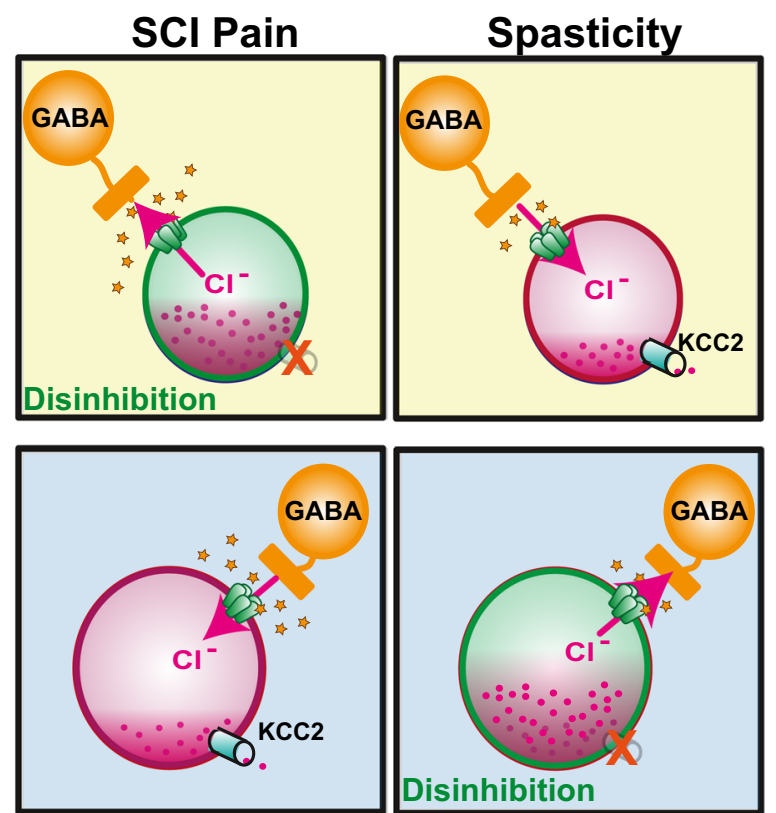

neurons results in disinhibition of sensory neurons that contributes to ongoing SCI pain by enhancing spinal responses to peripheral inputs (SCI Pain) [115]. Selective loss of KCC2 in the ventral horn results in disinhibition of motor neurons that can cause amplification of spinal reflex responses and spasticity (Spasticity) [117, 118]. If global changes in $\mathrm{KCC} 2$ expression occur following SCI, both neuropathic pain and spasticity could develop

found less reorganization of somatotopy in patients with neuropathic SCI pain compared to injury alone [133]. Additionally, an interesting preclinical study found that optogenetic stimulation of the hindlimb somatosensory cortex designed to reverse injury-induced loss of cortical activity in de-afferented regions prevented hindlimb allodynia following ischemic SCI [134].

The thalamus, which relays sensory information to the somatosensory cortex, also undergoes changes that are specifically associated with SCI pain. In particular, patients with SCI pain have reduced levels of thalamic GABA [135] and increased burst firing patterns [136], in addition to other metabolic abnormalities within the thalamus [137]. Animal models of contusion with either at- or below-level pain also develop spontaneous and hyperresponsive firing of thalamic neurons [138-140], though spontaneous firing in thalamic neurons may be transient following SCI [141]. Increased excitability of thalamic neurons could be due to reduced activity in neurons from the zona incerta region that normally keep tight inhibitory control over thalamic neurons, as has been shown following unilateral electrolytic lesion of the spinothalamic tract [142]. However, activated microglia are also detected in the thalamus, and both hindlimb sensitivity and increased thalamic neuron activity are reversed by blocking cysteine-cysteine chemokine ligand 21 (CCL21) within the thalamus or treatment with a cyclin-dependent kinase inhibitor that reduces microglial activation [138, 143]. Intrathecal delivery 
of anti-sense for $\mathrm{Na}(\mathrm{v}) 1.3$ also reduces spontaneous activity of thalamic neurons [144].

\section{Future Directions for SCI Pain Research}

In addition to clarifying mechanisms that contribute to the conscious experience of SCI pain, many other topics are of interest for future SCI pain research. For example, the relationship between mechanisms underlying different symptoms of SCI pain and at- versus below-level pain may improve identification of therapeutic approaches in individual patients. Because of the difficulty in separating pain from spasticity in rodent models, understanding the relationship between these sequelae may guide refinement of experimental models. There is a great deal of overlap between the presence of pain and depression in the SCI pain population, and a greater mechanistic understanding of the links between the two may lead to improved therapies for both. Finally, there may be relationships between patient characteristics, such as sex and age with the development and mechanisms of neuropathic pain.

\section{Symptom-Based Treatment Classification}

There is increasing interest in using quantitative sensory testing (QST) to classify patterns of pain symptoms that may benefit from specific therapeutic treatment. For example, two recent randomized placebo-controlled studies found that neuropathic pain patients with an irritable nociceptor phenotype, characterized by preserved response to cold, heat, and pinprick, have the best response to treatment with oxcarbazepine [58] and lignocaine 5\% patch [57], even though neuropathy was due to several different underlying causes. QST of patients with painful diabetic neuropathy likewise determined that treatment efficacy of gabapentin or the serotonin-norepinephrine reuptake inhibitor duloxetine correlates with specific clusters of sensory symptoms [56]. Use of QST in SCI pain populations identified two pain phenotypes: a moderate neuropathic pain cluster with significant loss of warm, cool, and vibration sensation and a severe neuropathic cluster characterized by less impairment of heat and cold pain detection [145]. A more recent study identified five separate symptom clusters, consistent with characteristics identified in other neuropathic pain conditions [146]. However, it is not yet clear that symptom clusters identified in the context of peripheral neuropathies will be directly applicable to SCI pain. In particular, the irritable nociceptor phenotype is thought to identify nociceptor hyperexcitability in peripheral neuropathic pain conditions [58, 147]. However, similar symptoms can arise as a consequence of spinothalamic tract dysfunction, but may result from spinal and supraspinal amplification of signals in residual and injured spinothalamic tract neurons [145]. Finally, even patients considered to have complete
SCI (ASIA A) can have unconscious preservation of some heat and cold sensation from below the lesion level, termed sensory discomplete [145, 148, 149]. Symptom clustering in SCI patients may be complicated by difficulties detecting sensory discomplete lesions by conventional examinations.

Some studies support the hypothesis that efficacy of pharmacological treatment will vary as a function of symptoms of SCI pain. The presence or absence of evoked pain has the greatest impact on treatment efficacy of oxcarbazepine, an anti-convulsant that blocks voltage-gated sodium channels [150], and pregabalin, with both drugs showing greater efficacy in patients without evoked SCI pain [151]). However, in patients with evoked pain, pregabalin is more effective against shooting pain, allodynia, and thermal hyperalgesia, whereas oxcarbazepine has greater efficacy on burning and pricking sensations [151]. Taken together, these results suggest that different symptoms of SCI pain could require different pharmacological approaches for effective management. Indeed, a very interesting case report found that even within the zone of at-level pain, QST yielded different profiles, and pharmacological treatment with pregabalin was only effective on the side that maintained normal intra-epidermal nerve fiber (IENF) innervation [152]. This demonstrates that even within at-level pain in the same patient, etiological differences might require different therapeutic approaches. However, a recent retrospective analysis of clinical trials for neuropathic pain highlighted the limitation of this approach when applied to currently used therapies, finding that of five drugs that alleviated neuropathic pain in clinical trials, only two, pregabalin and imipramine, had cluster-dependent beneficial effects in patients with a gain of sensory function [153].

\section{At-Level Versus Below-Level Pain}

It remains unclear whether at-level and below-level pain share mechanisms in common or have diverging etiologies that will require different treatment approaches. The rationale behind segregating these two types of pain is on the assumption that they might have distinct mechanisms that would inform treatment choices and promote greater correspondence between animal models and the clinical condition [154]. Because of its localization at the border zone of the injury, at-level pain has been hypothesized to result from damage to roots and nerves at or around the level of injury [10]. It typically develops in the acute stages following injury [9, 59]. Belowlevel pain has been ascribed to interruption of ascending sensory tracts, changes in sensory processing at the level of spinal cord and brain or development of phantom pain in deafferented regions, and develops over a longer timeframe than at-level pain [9].

A link between the two is suggested by multiple studies finding correlation between at-level allodynia or dysesthesia and below-level pain [155-158]. A recent study further found 
that below-level pain was associated with hypersensitivity to cold, touch, and pinprick both at-level and in dermatomes 810 segments rostral to the level of injury [68]. Other studies have found deficient above-level conditioned pain modulation [159] and greater above-level tonic suprathreshold pain [160] in SCI patients with neuropathic pain relative to those without pain or normal controls. Taken together, these studies suggest that some of the pathological processes contributing to belowlevel pain have widespread effects on sensory processing throughout the neuraxis.

A potential mechanistic link between at- and below-level pain is difficult to address in preclinical rodent models due to uncertainties in the rodent experience of below-level pain, as discussed above. Therefore, the relationship between at- and below-level pain would be best addressed in patient populations. However, very few clinical trials have compared treatment efficacy on at- versus below-level pain $[151,161]$. However, pregabalin and oxcarbazepine do not have different efficacy in at- versus below-level, but are more effective in patients without evoked pain [151]. Likewise, lamotrigine has greater efficacy against pain in patients with incomplete SCI, but not in at-versus belowlevel pain [161]. Nevertheless, a better understanding of whether effective pharmacological agents reduce pain both at- and below-level or only at one site or the other would begin to provide evidence as to whether the two share mechanisms in common, though this type of work is limited by the paucity of pharmaceuticals that alleviate neuropathic pain in general.

\section{Relationship Between Neuropathic Pain and Spasticity}

Considering the proposal that below-level evoked withdrawal responses may reflect spasticity [24], it is worth briefly exploring the relationship between SCI pain and spasticity. Up to $65 \%$ of SCI patients develop spasticity [162], which is characterized by muscle stiffness, increased resistance to passive stretch, increased stretch and extensor reflexes, and increased responsiveness to cutaneous input [163-165]. The multidimensional nature of spasticity has made it difficult to capture with a single clinical scale [166]. Like pain, spasticity can develop early in the course of SCI and persist indefinitely [162].

Increased stretch reflex activity could be due to either reduced threshold to elicit reflex response or increased amplification of the stretch reflex [162]. Therefore, sensitization of sensory structures could contribute to both pain and spasticity. The increased prevalence of spasticity in SCI patients with neuropathic pain suggests a mechanistic link between the two [167]. Furthermore, gabapentin, which is one of the frontline treatments for neuropathic pain [168], alleviates spasticity [169]. Experimentally, exercise alleviates spasticity $[170,171]$ and neuropathic SCI pain [92,
172, 173]. Conversely, the tricyclic anti-depressant amitryptiline alleviates neuropathic SCI pain [168] but may worsen spasticity [174] and intrathecal delivery of the $\mathrm{GABA}_{\mathrm{B}}$ receptor agonist baclofen is considered to be the most effective treatment for spasticity [6], but is ineffective or even exacerbates pain in SCI patients [175].

Spasticity has been studied preclinically in lesion models of varying severity placed anywhere from the cervical to sacral spinal cord (reviewed in [176]). These models have relied upon measuring muscle resistance in response to muscle stretch or cutaneous stimulation [171, 177] or changes in rate-dependent depression (RDD) of spinal H-reflex electromyogram (EMG) response [178]. RDD of the H-reflex is impaired in both patients and rodent models of spasticity [178, 179], but is also impaired in patients and rodents with painful diabetic neuropathy that is not associated with spasticity [ 180 , 181 ], so it may not be a biomarker that is unique to spasticity.

One potential mechanism in common between spasticity and neuropathic pain is the reduction of potassium-chloride cotransporter (KCC2), though spasticity may be primarily associated with reduced expression on motor neurons $[117,170]$ whereas neuropathic pain may involve reduced expression in dorsal horn neurons $[115,180]$ (Fig. 3). KCC2 maintains normal chloride homeostasis within neurons by passively allowing efflux of chloride along the potassium concentration gradient [182]. Reduction in membrane KCC2 expression causes an accumulation of intraneuronal chloride, leading to altered chloride reversal potential and reduced inhibition when ionotropic $\mathrm{GABA}_{\mathrm{A}}$ receptors are activated [116]. Activated microglia and increased BDNF can both lead to reduced KCC2 expression [183], and SCI is associated with chronically increased microglia [76] and acutely increased BDNF [184, 185]. Loss of descending serotonin fibers may also contribute to reduced $\mathrm{KCC} 2$ as activation of spinal 5-HT2A receptors alleviates spasticity by restoring KCC2 function [118]. Spinal KCC2 expression following SCI is restored by passive exercise [170], which has beneficial effects against both spasticity and SCI pain [171, 172]. Therefore, in cases of KCC2 reduction on both dorsal horn and motor neurons, symptoms could manifest as both pain and spasticity, whereas reduction in one or the other would lead to pain or spasticity, respectively. Treatments that counteract the loss of KCC2 function, such as acetazolamide [186], may be beneficial for treatment of both symptoms.

The extent to which measures of evoked neuropathic pain in rodent models of SCI may partially reflect spasticity makes it possible that mechanisms ascribed to development of neuropathic pain instead contribute to spasticity, or both. Better characterization of the relationship between presence of evoked withdrawal responses and spasticity may clarify the nature of this relationship and reveal commonalities and dissimilarities between the etiologies of neuropathic pain and spasticity following SCI. 
Relationship Between Neuropathic Pain, Depression, and Anxiety

SCI is associated with a high prevalence of both neuropathic pain and depression, with the two co-occurring in $22-35 \%$ of patients [187]. The presence and severity of pain is associated with depression in the SCI patient population, and association studies suggest that the presence of pain causes depression [187-193]. Likewise, patients with SCI are at greater risk for developing anxiety [193-195], especially those with pain [190]. However, it is not clear whether the link between pain, anxiety, and depression is psychosomatic or rooted in physical changes to the nervous system that affect both sensory and affective processing. For example, psychological factors such as elevated hopelessness/helplessness and catastrophizing correlate with pain-related disability and development of depression in SCI patients $[194,196]$. However, physical changes, such as elevated levels of circulating pro-inflammatory cytokines are also associated with development of both pain (for a comprehensive review, see [197]) and depression [198-200].

Clinically, SCI is associated with increased levels of circulating cytokines [201, 202], particularly in patients with SCI neuropathic pain [203]. Furthermore, cerebrospinal fluid levels of tumor necrosis factor receptor 1 (TNF-R1) are correlated with presence of neuropathic pain $24 \mathrm{~h}$ following SCI, though there is no association between pain and cytokine levels 7 months later [204]. Placing SCI patients on an antiinflammatory diet that reduces circulating cytokines has been shown to have some beneficial effects on both depression [205] and pain [206].

In contused rats with SCI of varying severities, hindlimb withdrawal thresholds are significantly, but modestly, lower in a group of rats displaying behaviors consistent with anxiety and depression that have elevated levels of circulating spinal and hippocampal pro-inflammatory cytokines [48]. Importantly, the presence of anxiety and depression does not impact locomotor function, indicating that these symptoms are not a consequence of reduced physical capability [48]. Depression alone is not associated with sensory outcomes $[48,51]$. Cytokine expression and concomitant microglial activation are elevated throughout the brain in response to thoracic injury and are associated with both impaired cognitive performance and symptoms of depression [207-209]). Treatment with CR8, a selective cyclin-dependent kinase inhibitor that reduces cell cycle genes and protein expression, reduces pro-inflammatory cytokine expression and microglial activation and is associated with improvement of depressive symptoms and cognitive function, implicating cell cycle activation in the pathophysiology of these sequelae [209]. Cell cycle activation has also been linked to reduced hindlimb withdrawal threshold $[54,109,138,210]$, suggesting an additional common pathway that can be targeted to alleviate both consequences of SCI. However, additional studies are needed to better parse the relationship between SCI pain and depression.

\section{Mechanisms of Pain in Male Versus Female SCI Pain}

Like a majority of pain studies [23], SCI pain has been predominantly studied in young male rodents [17]. However, upwards of $70 \%$ of SCI patients are male [211], so this choice can be more readily justified than in other pain models. Additionally, unlike other pain syndromes, the prevalence of neuropathic pain and reported pain intensity is equivalent between male and female patients [212,213], though female SCI patients may have an increased overall pain prevalence (including nociceptive pain) $[212,214]$. Nevertheless, recent data emerging from other neuropathic pain models suggest that male and female subjects may process painful stimuli in different ways that may necessitate different treatment approaches [215].

Only a few studies have evaluated experimental SCI pain in both male and female subjects. Following contusion injury, male rats have a greater reduction in hindlimb mechanical withdrawal thresholds than females, though rats of both sexes develop increased responsiveness to thermal stimuli [216]. However, operant testing in a model of quisqualate injection that causes excitotoxic SCI suggests that female rats have more thermal hyperalgesia and less cold hyperalgesia than their male counterparts [217]. Though these data suggest that the magnitude of symptoms of SCI pain may differ between the sexes, depending in part on the lesion model, neither addressed potential mechanistic differences that could account for these dissimilarities. Further studies on the topic are needed.

\section{Effect of Age and Duration on SCI Neuropathic Pain}

There is a greater prevalence of neuropathic pain in SCI patients aged 50 years and older (51\%) than for those aged less than 50 years (38\%) [11]. This suggests that increased age at the time of injury correlates with development of SCI pain, as has been reported [212], because duration of injury does not correlate with presence of pain $[212,213]$. In contrast, another study found that patients that develop below-level neuropathic pain within 12 months following SCI are significantly younger than patients that do not develop below-level pain, whereas patient age does not play a role in the prevalence of at-level pain [59]. Therefore, the consequence of age on the development of SCI pain remains unresolved.

A majority of preclinical studies of SCI pain have used young rats [17]. There is limited evidence that age affects neuropathic pain outcomes following experimental SCI, but the effects of age have been infrequently studied. Comparison of the effect of a T13 hemisection on locomotor and pain outcomes in 40-day-old (young), 60-day-old (adult), and 1-year 
old (middle-aged) male rats found reduced locomotor recovery in middle-aged rats, but increased hindlimb sensitivity to von Frey stimulation only in young rats [218, 219]. As aging is associated with anatomical and functional changes to the somatosensory system (reviewed in [220]) and differences in immune responses to SCI [221], additional studies may be warranted to identify mechanistic differences that contribute to pain in older versus younger subjects. This may be particularly pressing if age of injury predisposes individuals to development of SCI pain, as the average age at the time of SCI has increased from 29 years old in the 1970s to 42 years old in 2015 [20]. Additional clinical and preclinical work may yield important insights as to the role of aging in development of SCI pain.

Although the description and presence of neuropathic pain does not change as a function of SCI duration in the clinical population [212, 213], underlying mechanisms governing the maintenance of pain could evolve as a function of time. Very few studies have evaluated SCI pain at time points longer than a few months, and a majority of mechanistic studies have remained confined to these relatively short durations. Since SCI pain persists over the lifetime of afflicted individuals, studies evaluating the chronicity of underlying mechanisms may illuminate novel therapeutic avenues.

\section{Conclusions}

Studying SCI-induced neuropathic pain remains an area of high priority to guide development of novel therapeutic approaches for clinical translation. Though preclinical SCI pain research has increased substantially over the last decade [17], concerns over methods for evaluating the presence of neuropathic pain in SCI rodents have led to uncertainty as to the relevance of this research to the clinical experience of pain. Increased use of operant conditioning tasks alongside measures of evoked withdrawals will improve the relevance of preclinical findings and allow the field to answer important mechanistic questions that may improve clinical treatment of this debilitating consequence of SCI. Consequently, until an improved understanding of mechanisms underlying neuropathic pain leads to development and implementation of effective therapeutic options, studying this topic should remain an area of high priority even in the face of rapidly advancing technologies, such as stem cell transplantation [222] or brainmachine interfaces [223], aimed to overcome paralysis.

Required Author Forms Disclosure forms provided by the authors are available with the online version of this article.

\section{Compliance with Ethical Standards}

Conflict of Interest The authors declare that they have no conflicts of interest.

\section{References}

1. Davis L, Martin J. Studies upon spinal cord injuries; the nature and treatment of pain. J Neurosurg. 1947;4(6):483-91.

2. Simpson LA, Eng JJ, Hsieh JT, Wolfe DL, Spinal Cord Injury Rehabilitation Evidence SCIRE Research T. The health and life priorities of individuals with spinal cord injury: a systematic review. J Neurotrauma. 2012;29(8):1548-55.

3. Widerstrom-Noga EG, Felipe-Cuervo E, Broton JG, Duncan RC, Yezierski RP. Perceived difficulty in dealing with consequences of spinal cord injury. Arch Phys Med Rehabil. 1999;80(5):580-6.

4. Lundqvist C, Siosteen A, Blomstrand C, Lind B, Sullivan M. Spinal cord injuries. Clinical, functional, and emotional status. Spine (Phila Pa 1976). 1991;16(1):78-83.

5. Westgren N, Levi R. Quality of life and traumatic spinal cord injury. Arch Phys Med Rehabil. 1998;79(11):1433-9.

6. Burchiel KJ, Hsu FP. Pain and spasticity after spinal cord injury: mechanisms and treatment. Spine (Phila Pa 1976). 2001;26(24 Suppl):S146-60.

7. Widerstrom-Noga EG, Turk DC. Types and effectiveness of treatments used by people with chronic pain associated with spinal cord injuries: influence of pain and psychosocial characteristics. Spinal Cord. 2003;41(11):600-9.

8. Finnerup NB, Johannesen IL, Sindrup SH, Bach FW, Jensen TS. Pain and dysesthesia in patients with spinal cord injury: a postal survey. Spinal Cord. 2001;39(5):256-62.

9. Siddall PJ, McClelland JM, Rutkowski SB, Cousins MJ. A longitudinal study of the prevalence and characteristics of pain in the first 5 years following spinal cord injury. Pain. 2003;103(3):249-57.

10. Bryce TN, Biering-Sorensen F, Finnerup NB, et al. International spinal cord injury pain classification: part I. Background and description. March 6-7, 2009. Spinal Cord. 2012;50(6):413-7.

11. Burke D, Fullen BM, Stokes D, Lennon O. Neuropathic pain prevalence following spinal cord injury: a systematic review and meta-analysis. Eur J Pain. 2017;21(1):29-44.

12. Schuld C, Franz S, Bruggemann K, et al. International standards for neurological classification of spinal cord injury: impact of the revised worksheet (revision 02/13) on classification performance. J Spinal Cord Med. 2016;39(5):504-12.

13. Finnerup NB, Jensen MP, Norrbrink C, et al. A prospective study of pain and psychological functioning following traumatic spinal cord injury. Spinal Cord. 2016;54(10):816-21.

14. Werhagen L, Budh CN, Hultling C, Molander C. Neuropathic pain after traumatic spinal cord injury - relations to gender, spinal level, completeness, and age at the time of injury. Spinal Cord. 2004;42(12):665-73.

15. Gruener G, Dyck PJ. Quantitative sensory testing: methodology, applications, and future directions. J Clin Neurophysiol. 1994;11(6):568-83.

16. Nakae A, Nakai K, Yano K, et al. The animal model of spinal cord injury as an experimental pain model. J Biomed Biotechnol. 2011;2011:939023.

17. Kramer JL, Minhas NK, Jutzeler CR, et al. Neuropathic pain following traumatic spinal cord injury: models, measurement, and mechanisms. J Neurosci Res. 2017;95(6):1295-306.

18. Yezierski RP, Liu S, Ruenes GL, Kajander KJ, Brewer KL. Excitotoxic spinal cord injury: behavioral and morphological characteristics of a central pain model. Pain. 1998;75(1):141-55.

19. Wang G, Thompson SM. Maladaptive homeostatic plasticity in a rodent model of central pain syndrome: thalamic hyperexcitability after spinothalamic tract lesions. J Neurosci. 2008;28(46):11959-69.

20. Center NSCIS. Facts and Figures at a Glance Birmingham, AL: University of Alabama at Birmingham. 2016. 
21. Detloff MR, Wade RE, Jr., Houle JD. Chronic at- and below-level pain after moderate unilateral cervical spinal cord contusion in rats. J Neurotrauma. 2013;30(10):884-90.

22. Watson JL, Hala TJ, Putatunda R, Sannie D, Lepore AC. Persistent at-level thermal hyperalgesia and tactile allodynia accompany chronic neuronal and astrocyte activation in superficial dorsal horn following mouse cervical contusion spinal cord injury. PLoS One. 2014;9(9):e109099.

23. Mogil JS. Animal models of pain: progress and challenges. Nat Rev Neurosci. 2009;10(4):283-94.

24. Baastrup C, Maersk-Moller CC, Nyengaard JR, Jensen TS, Finnerup NB. Spinal-, brainstem- and cerebrally mediated responses at- and below-level of a spinal cord contusion in rats: evaluation of pain-like behavior. Pain. 2010;151(3):670-9.

25. van Gorp S, Deumens R, Leerink M, et al. Translation of the rat thoracic contusion model; part 1-supraspinally versus spinally mediated pain-like responses and spasticity. Spinal Cord. 2014;52(7): 524-8.

26. Advokat C. Spinal transection increases the potency of clonidine on the tail-flick and hindlimb flexion reflexes. Eur J Pharmacol. 2002;437(1-2):63-7.

27. Kauppila T, Kontinen VK, Pertovaara A. Influence of spinalization on spinal withdrawal reflex responses varies depending on the submodality of the test stimulus and the experimental pathophysiological condition in the rat. Brain Res. 1998;797(2):234-42.

28. M'Dahoma S, Bourgoin S, Kayser V, et al. Spinal cord transectioninduced allodynia in rats - behavioral, physiopathological and pharmacological characterization. PLoS One. 2014;9(7):e102027.

29. Jergova S, Gordon CE, Gajavelli S, Sagen J. Experimental gene therapy with serine-histogranin and endomorphin 1 for the treatment of chronic neuropathic pain. Front Mol Neurosci. 2017;10:406.

30. Berridge KC. Progressive degradation of serial grooming chains by descending decerebration. Behav Brain Res. 1989;33(3):241-53.

31. Matthies BK, Franklin KB. Formalin pain is expressed in decerebrate rats but not attenuated by morphine. Pain. 1992;51(2): 199-206.

32. Woolf CJ. Long term alterations in the excitability of the flexion reflex produced by peripheral tissue injury in the chronic decerebrate rat. Pain. 1984;18(4):325-43.

33. LaBuda CJ, Fuchs PN. A behavioral test paradigm to measure the aversive quality of inflammatory and neuropathic pain in rats. Exp Neurol. 2000;163(2):490-4.

34. LaGraize SC, Labuda CJ, Rutledge MA, Jackson RL, Fuchs PN. Differential effect of anterior cingulate cortex lesion on mechanical hypersensitivity and escape/avoidance behavior in an animal model of neuropathic pain. Exp Neurol. 2004;188(1):139-48.

35. Harte SE, Meyers JB, Donahue RR, Taylor BK, Morrow TJ. Mechanical conflict system: a novel operant method for the assessment of nociceptive behavior. PLoS One. 2016;11(2): e0150164.

36. King T, Vera-Portocarrero L, Gutierrez T, et al. Unmasking the tonic-aversive state in neuropathic pain. Nat Neurosci. 2009;12(11):1364-6.

37. Lee-Kubli CA, Ingves M, Henry KW, et al. Analysis of the behavioral, cellular and molecular characteristics of pain in severe rodent spinal cord injury. Exp Neurol. 2016;278:91-104.

38. Wu Z, Yang Q, Crook RJ, O'Neil RG, Walters ET. TRPV1 channels make major contributions to behavioral hypersensitivity and spontaneous activity in nociceptors after spinal cord injury. Pain. 2013;154(10):2130-41.

39. Vierck CJ, Cannon RL, Acosta-Rua AJ. Evaluation of lateral spinal hemisection as a preclinical model of spinal cord injury pain. Exp Brain Res. 2013;228(3):305-12.
40. Lau D, Harte SE, Morrow TJ, et al. Herpes simplex virus vectormediated expression of interleukin-10 reduces below-level central neuropathic pain after spinal cord injury. Neurorehabil Neural Repair. 2012;26(7):889-97.

41. Galan-Arriero I, Avila-Martin G, Ferrer-Donato A, et al. Oral administration of the p38alpha MAPK inhibitor, UR13870, inhibits affective pain behavior after spinal cord injury. Pain. 2014;155(10):2188-98.

42. Yang Q, Wu Z, Hadden JK, et al. Persistent pain after spinal cord injury is maintained by primary afferent activity. J Neurosci. 2014;34(32):10765-9.

43. Vierck CJ, Baastrup C, Maersk-Moller C, et al. A preclinical model of hyperalgesia following spinal stenosis/compression. Eur J Pain. 2015;19(8):1158-67.

44. Okun A, DeFelice M, Eyde N, et al. Transient inflammationinduced ongoing pain is driven by TRPV1 sensitive afferents. Mol Pain. 2011;7:4

45. Sufka KJ. Conditioned place preference paradigm: a novel approach for analgesic drug assessment against chronic pain. Pain. 1994;58(3):355-66.

46. Woller SA, Moreno GL, Hart N, et al. Analgesia or addiction?: implications for morphine use after spinal cord injury. J Neurotrauma. 2012;29(8):1650-62.

47. Mills CD, Grady JJ, Hulsebosch CE. Changes in exploratory behavior as a measure of chronic central pain following spinal cord injury. J Neurotrauma. 2001;18(10):1091-105.

48. Maldonado-Bouchard S, Peters K, Woller SA, et al. Inflammation is increased with anxiety- and depression-like signs in a rat model of spinal cord injury. Brain Behav Immun. 2016;51:176-95.

49. Le J, Dorstyn D. Anxiety prevalence following spinal cord injury: a meta-analysis. Spinal Cord. 2016;54(8):626.

50. Krause JS, Kemp B, Coker J. Depression after spinal cord injury: relation to gender, ethnicity, aging, and socioeconomic indicators. Arch Phys Med Rehabil. 2000;81(8):1099-109.

51. Luedtke K, Bouchard SM, Woller SA, et al. Assessment of depression in a rodent model of spinal cord injury. J Neurotrauma. 2014;31(12):1107-21.

52. Calmels P, Mick G, Perrouin-Verbe B, Ventura M, Sofmer. Neuropathic pain in spinal cord injury: identification, classification, evaluation. Ann Phys Rehabil Med. 2009;52(2):83-102.

53. Langford DJ, Bailey AL, Chanda ML, et al. Coding of facial expressions of pain in the laboratory mouse. Nat Methods. 2010;7(6):447-9.

54. Wu J, Zhao Z, Zhu X, et al. Cell cycle inhibition limits development and maintenance of neuropathic pain following spinal cord injury. Pain. 2016;157(2):488-503.

55. Schneider LE, Henley KY, Turner OA, et al. Application of the rat grimace scale as a marker of supraspinal pain sensation after cervical spinal cord injury. J Neurotrauma. 2017;34(21):2982-93.

56. Bouhassira D, Wilhelm S, Schacht A, et al. Neuropathic pain phenotyping as a predictor of treatment response in painful diabetic neuropathy: data from the randomized, double-blind, COMBO-DN study. Pain. 2014;155(10):2171-9.

57. Demant DT, Lund K, Finnerup NB, et al. Pain relief with lidocaine $5 \%$ patch in localized peripheral neuropathic pain in relation to pain phenotype: a randomised, double-blind, and placebo-controlled, phenotype panel study. Pain. 2015;156(11):2234-44.

58. Demant DT, Lund K, Vollert J, et al. The effect of oxcarbazepine in peripheral neuropathic pain depends on pain phenotype: a randomised, double-blind, placebo-controlled phenotype-stratified study. Pain. 2014;155(11):2263-73.

59. Finnerup NB, Norrbrink C, Trok K, et al. Phenotypes and predictors of pain following traumatic spinal cord injury: a prospective study. J Pain. 2014;15(1):40-8.

60. Christensen MD, Hulsebosch CE. Chronic central pain after spinal cord injury. J Neurotrauma. 1997;14(8):517-37. 
61. Bruce JC, Oatway MA, Weaver LC. Chronic pain after clipcompression injury of the rat spinal cord. Exp Neurol. 2002;178(1):33-48.

62. Carlton SM, Du J, Tan HY, et al. Peripheral and central sensitization in remote spinal cord regions contribute to central neuropathic pain after spinal cord injury. Pain. 2009;147(1-3):265-76.

63. Densmore VS, Kalous A, Keast JR, Osborne PB. Above-level mechanical hyperalgesia in rats develops after incomplete spinal cord injury but not after cord transection, and is reversed by amitriptyline, morphine and gabapentin. Pain. 2010;151(1):184-93.

64. Siddall PJ, Middleton JW. A proposed algorithm for the management of pain following spinal cord injury. Spinal Cord. 2006;44(2):67-77.

65. Ko HY, Park JH, Shin YB, Baek SY. Gross quantitative measurements of spinal cord segments in human. Spinal Cord. 2004;42(1): $35-40$.

66. de Sousa BN, Horrocks LA. Development of rat spinal cord I. Weight and length with a method for rapid removal. Developmental Neuroscience. 1979;2:115-21.

67. Walters ET. Neuroinflammatory contributions to pain after SCI: roles for central glial mechanisms and nociceptor-mediated host defense. Exp Neurol. 2014;258:48-61.

68. Vogel C, Rukwied R, Stockinger L, et al. Functional characterization of at-level hypersensitivity in patients with spinal cord injury. J Pain. 2017;18(1):66-78.

69. Widerstrom-Noga E. Chronic pain and nonpainful sensations after spinal cord injury: is there a relation? Clin J Pain. 2003;19(1):39-47.

70. Christensen MD, Everhart AW, Pickelman JT, Hulsebosch CE. Mechanical and thermal allodynia in chronic central pain following spinal cord injury. Pain. 1996;68(1):97-107.

71. Kim HT, Kim T, Novotny B, et al. Thermal hyperalgesia assessment for rats after spinal cord injury: developing a valid and useful pain index. Spine J. 2014;14(6):984-9.

72. Hargreaves K, Dubner R, Brown F, Flores C, Joris J. A new and sensitive method for measuring thermal nociception in cutaneous hyperalgesia. Pain. 1988;32(1):77-88.

73. Finnerup NB, Johannesen IL, Fuglsang-Frederiksen A, Bach FW, Jensen TS. Sensory function in spinal cord injury patients with and without central pain. Brain. 2003;126(Pt 1):57-70.

74. Hama A, Sagen J. Sustained antinociceptive effect of cannabinoid receptor agonist WIN 55,212-2 over time in rat model of neuropathic spinal cord injury pain. J Rehabil Res Dev. 2009;46(1): 135-43.

75. DomBourian MG, Turner NA, Gerovac TA, et al. B1 and TRPV-1 receptor genes and their relationship to hyperalgesia following spinal cord injury. Spine (Phila Pa 1976). 2006;31(24):2778-82.

76. Hains BC, Waxman SG. Activated microglia contribute to the maintenance of chronic pain after spinal cord injury. J Neurosci. 2006;26(16):4308-17.

77. Knerlich-Lukoschus F, Juraschek M, Blomer U, et al. Forcedependent development of neuropathic central pain and timerelated CCL2/CCR 2 expression after graded spinal cord contusion injuries of the rat. J Neurotrauma. 2008;25(5):427-48.

78. Widerstrom-Noga EG, Turk DC. Exacerbation of chronic pain following spinal cord injury. J Neurotrauma. 2004;21(10): 1384-95.

79. Hao JX, Yu W, Xu XJ, Wiesenfeld-Hallin Z. Capsaicin-sensitive afferents mediate chronic cold, but not mechanical, allodynia-like behavior in spinally injured rats. Brain Res. 1996;722(1-2):177-80.

80. Kim J, Yoon YW, Hong SK, Na HS. Cold and mechanical allodynia in both hindpaws and tail following thoracic spinal cord hemisection in rats: time courses and their correlates. Neurosci Lett. 2003;343(3):200-4.

81. Lindsey AE, LoVerso RL, Tovar CA, et al. An analysis of changes in sensory thresholds to mild tactile and cold stimuli after experimental spinal cord injury in the rat. Neurorehabil Neural Repair. 2000;14(4):287-300.

82. Yoon YW, Dong H, Arends JJ, Jacquin MF. Mechanical and cold allodynia in a rat spinal cord contusion model. Somatosens Mot Res. 2004;21(1):25-31.

83. Gao T, Hao JX, Wiesenfeld-Hallin Z, Xu XJ. Quantitative test of responses to thermal stimulation in spinally injured rats using a Peltier thermode: a new approach to study cold allodynia. J Neurosci Methods. 2013;212(2):317-21.

84. Allchorne AJ, Broom DC, Woolf CJ. Detection of cold pain, cold allodynia and cold hyperalgesia in freely behaving rats. Mol Pain. 2005; $1: 36$.

85. Walters ET. Nociceptors as chronic drivers of pain and hyperreflexia after spinal cord injury: an adaptive-maladaptive hyperfunctional state hypothesis. Front Physiol. 2012;3:309.

86. Wrigley PJ, Siddall PJ, Gustin SM. New evidence for preserved somatosensory pathways in complete spinal cord injury: a fMRI study. Hum Brain Mapp. 2018;39(1):588-98.

87. Bedi SS, Yang Q, Crook RJ, et al. Chronic spontaneous activity generated in the somata of primary nociceptors is associated with pain-related behavior after spinal cord injury. J Neurosci. 2010;30(44):14870-82.

88. Ritter DM, Zemel BM, Hala TJ, et al. Dysregulation of Kv3.4 channels in dorsal root ganglia following spinal cord injury. $\mathrm{J}$ Neurosci. 2015;35(3):1260-73.

89. Zhang X, Chen Y, Wang C, Huang LY. Neuronal somatic ATP release triggers neuron-satellite glial cell communication in dorsal root ganglia. Proc Natl Acad Sci U S A. 2007;104(23):9864-9.

90. Gu Y, Chen Y, Zhang X, et al. Neuronal soma-satellite glial cell interactions in sensory ganglia and the participation of purinergic receptors. Neuron Glia Biol. 2010;6(1):53-62.

91. Jasmin L, Vit JP, Bhargava A, Ohara PT. Can satellite glial cells be therapeutic targets for pain control? Neuron Glia Biol. 2010;6(1): 63-71.

92. Detloff MR, Smith EJ, Quiros Molina D, Ganzer PD, Houle JD. Acute exercise prevents the development of neuropathic pain and the sprouting of non-peptidergic (GDNF- and artemin-responsive) c-fibers after spinal cord injury. Exp Neurol. 2014;255:38-48.

93. Christensen MD, Hulsebosch CE. Spinal cord injury and antiNGF treatment results in changes in CGRP density and distribution in the dorsal horn in the rat. Exp Neurol. 1997;147(2):463-75.

94. Krenz NR, Meakin SO, Krassioukov AV, Weaver LC. Neutralizing intraspinal nerve growth factor blocks autonomic dysreflexia caused by spinal cord injury. J Neurosci. 1999;19(17):7405-14.

95. Hou S, Duale H, Rabchevsky AG. Intraspinal sprouting of unmyelinated pelvic afferents after complete spinal cord injury is correlated with autonomic dysreflexia induced by visceral pain. Neuroscience. 2009;159(1):369-79.

96. Ramer LM, van Stolk AP, Inskip JA, Ramer MS, Krassioukov AV. Plasticity of TRPV1-expressing sensory neurons mediating autonomic dysreflexia following spinal cord injury. Front Physiol. 2012;3:257.

97. Ondarza AB, Ye Z, Hulsebosch CE. Direct evidence of primary afferent sprouting in distant segments following spinal cord injury in the rat: colocalization of GAP-43 and CGRP. Exp Neurol. 2003;184(1):373-80.

98. Cameron AA, Smith GM, Randall DC, Brown DR, Rabchevsky AG. Genetic manipulation of intraspinal plasticity after spinal cord injury alters the severity of autonomic dysreflexia. J Neurosci. 2006;26(11):2923-32.

99. Widerstrom-Noga E, Cruz-Almeida Y, Krassioukov A. Is there a relationship between chronic pain and autonomic dysreflexia in persons with cervical spinal cord injury? J Neurotrauma. 2004;21(2):195-204. 
100. Walters ET. How is chronic pain related to sympathetic dysfunction and autonomic dysreflexia following spinal cord injury? Auton Neurosci. 2018;209:79-89.

101. Nesic O, Lee J, Johnson KM, et al. Transcriptional profiling of spinal cord injury-induced central neuropathic pain. J Neurochem. 2005;95(4):998-1014.

102. Detloff MR, Fisher LC, McGaughy V, et al. Remote activation of microglia and pro-inflammatory cytokines predict the onset and severity of below-level neuropathic pain after spinal cord injury in rats. Exp Neurol. 2008;212(2):337-47.

103. Gwak YS, Kang J, Unabia GC, Hulsebosch CE. Spatial and temporal activation of spinal glial cells: role of gliopathy in central neuropathic pain following spinal cord injury in rats. Exp Neurol. 2012;234(2):362-72.

104. Crown ED, Gwak YS, Ye Z, Johnson KM, Hulsebosch CE. Activation of 38 MAP kinase is involved in central neuropathic pain following spinal cord injury. Exp Neurol.2008;213(2):25767.

105. Putatunda R, Hala TJ, Chin J, Lepore AC. Chronic at-level thermal hyperalgesia following rat cervical contusion spinal cord injury is accompanied by neuronal and astrocyte activation and loss of the astrocyte glutamate transporter, GLT1, in superficial dorsal horn. Brain Res. 2014;1581:64-79.

106. Nesic O, Guest JD, Zivadinovic D, et al. Aquaporins in spinal cord injury: the janus face of aquaporin 4. Neuroscience. 2010;168(4): 1019-35.

107. Garrido-Mesa N, Zarzuelo A, Galvez J. What is behind the nonantibiotic properties of minocycline? Pharmacol Res. 2013;67(1): $18-30$.

108. Matyas JJ, O'Driscoll CM, Yu L, et al. Truncated TrkB.T1-mediated astrocyte dysfunction contributes to impaired motor function and neuropathic pain after spinal cord injury. J Neurosci. 2017;37(14):3956-71.

109. Wu J, Renn CL, Faden AI, Dorsey SG. TrkB.T1 contributes to neuropathic pain after spinal cord injury through regulation of cell cycle pathways. J Neurosci. 2013;33(30):12447-63.

110. Chen MJ, Kress B, Han X, et al. Astrocytic CX43 hemichannels and gap junctions play a crucial role in development of chronic neuropathic pain following spinal cord injury. Glia. 2012;60(11): 1660-70.

111. Falnikar A, Hala TJ, Poulsen DJ, Lepore AC. GLT1 overexpression reverses established neuropathic pain-related behavior and attenuates chronic dorsal horn neuron activation following cervical spinal cord injury. Glia. 2016;64(3):396-406.

112. Drew GM, SiddallPJ, Duggan AW. Mechanicalallodynia following contusion injury of the rat spinal cord is associated with loss of GABAergic inhibition in the dorsal horn. Pain. 2004;109(3): 379-88.

113. Meisner JG, Marsh AD, Marsh DR. Loss of GABAergic interneurons in laminae I-III of the spinal cord dorsal horn contributes to reduced GABAergic tone and neuropathic pain after spinal cord injury. J Neurotrauma. 2010;27(4):729-37.

114. Berrocal YA, Almeida VW, Puentes R, et al. Loss of central inhibition: implications for behavioral hypersensitivity after contusive spinal cord injury in rats. Pain Res Treat. 2014;2014:178278.

115. Sanchez-Brualla I, Boulenguez P, Brocard C, et al. Activation of 5$\mathrm{HT} 2 \mathrm{~A}$ receptors restores $\mathrm{KCC} 2$ function and reduces neuropathic pain after spinal cord injury. Neuroscience. 2017.

116. Coull JA, Boudreau D, Bachand K, et al. Trans-synaptic shift in anion gradient in spinal lamina I neurons as a mechanism of neuropathic pain. Nature. 2003;424(6951):938-42.

117. Boulenguez P, Liabeuf S, Bos R, et al. Down-regulation of the potassium-chloride cotransporter $\mathrm{KCC} 2$ contributes to spasticity after spinal cord injury. Nat Med. 2010;16(3):302-7.

118. Bos R, Sadlaoud K, Boulenguez P, et al. Activation of 5-HT2A receptors upregulates the function of the neuronal $\mathrm{K}-\mathrm{Cl}$ cotransporter KCC2. Proc Natl Acad Sci U S A. 2013;110(1): 348-53.

119. Sivilotti L, Woolf CJ. The contribution of GABAA and glycine receptors to central sensitization: disinhibition and touch-evoked allodynia in the spinal cord. J Neurophysiol. 1994;72(1):169-79.

120. Millan MJ. Descending control of pain. Prog Neurobiol. 2002;66(6):355-474.

121. Hains BC, Everhart AW, Fullwood SD, Hulsebosch CE. Changes in serotonin, serotonin transporter expression and serotonin denervation supersensitivity: involvement in chronic central pain after spinal hemisection in the rat. Exp Neurol. 2002;175(2):347-62.

122. Oatway MA, Chen Y, Weaver LC. The 5-HT3 receptor facilitates at-level mechanical allodynia following spinal cord injury. Pain. 2004;110(1-2):259-68.

123. Hains BC, Fullwood SD, Eaton MJ, Hulsebosch CE. Subdural engraftment of serotonergic neurons following spinal hemisection restores spinal serotonin, downregulates serotonin transporter, and increases BDNF tissue content in rat. Brain Res. 2001;913(1):35-46.

124. Conte D, Legg ED, McCourt AC, et al. Transmitter content, origins and connections of axons in the spinal cord that possess the serotonin (5-hydroxytryptamine) 3 receptor. Neuroscience. 2005;134(1):165-73.

125. Kia HK, Miquel MC, McKernan RM, et al. Localization of 5-HT3 receptors in the rat spinal cord: immunohistochemistry and in situ hybridization. Neuroreport. 1995;6(2):257-61.

126. Chen Y, Oatway MA, Weaver LC. Blockade of the 5-HT3 receptor for days causes sustained relief from mechanical allodynia following spinal cord injury. J Neurosci Res. 2009;87(2):418-24.

127. Hains BC, Willis WD, Hulsebosch CE. Serotonin receptors 5HT1A and 5-HT3 reduce hyperexcitability of dorsal horn neurons after chronic spinal cord hemisection injury in rat. Exp Brain Res. 2003;149(2):174-86.

128. Bowker RM, Westlund KN, Sullivan MC, Wilber JF, Coulter JD. Descending serotonergic, peptidergic and cholinergic pathways from the raphe nuclei: a multiple transmitter complex. Brain Res. 1983;288(1-2):33-48.

129. Nicholas AP, Pieribone VA, Arvidsson U, Hokfelt T. Serotonin-, substance P- and glutamate/aspartate-like immunoreactivities in medullo-spinal pathways of rat and primate. Neuroscience. 1992;48(3):545-59.

130. Nardone R, Holler Y, Brigo F, et al. Functional brain reorganization after spinal cord injury: systematic review of animal and human studies. Brain Res. 2013;1504:58-73.

131. Tandon S, Kambi N, Lazar L, Mohammed H, Jain N. Large-scale expansion of the face representation in somatosensory areas of the lateral sulcus after spinal cord injuries in monkeys. J Neurosci. 2009;29(38):12009-19.

132. Wrigley PJ, Press SR, Gustin SM, et al. Neuropathic pain and primary somatosensory cortex reorganization following spinal cord injury. Pain. 2009;141(1-2):52-9.

133. Jutzeler CR, Freund P, Huber E, Curt A, Kramer JLK. Neuropathic pain and functional reorganization in the primary sensorimotor cortex after spinal cord injury. J Pain. 2015;16(12):1256-67.

134. Xiong W, Ping X, Ripsch MS, et al. Enhancing excitatory activity of somatosensory cortex alleviates neuropathic pain through regulating homeostatic plasticity. Sci Rep. 2017;7(1):12743.

135. Gustin SM, Wrigley PJ, Youssef AM, et al. Thalamic activity and biochemical changes in individuals with neuropathic pain after spinal cord injury. Pain. 2014;155(5):1027-36.

136. Lenz FA, Kwan HC, Dostrovsky JO, Tasker RR. Characteristics of the bursting pattern of action potentials that occurs in the thalamus of patients with central pain. Brain Res. 1989;496(1-2):357-60.

137. Widerstrom-Noga E, Cruz-Almeida Y, Felix ER, Pattany PM. Somatosensory phenotype is associated with thalamic 
metabolites and pain intensity after spinal cord injury. Pain. 2015;156(1):166-74.

138. Wu J, Raver C, Piao C, Keller A, Faden AI. Cell cycle activation contributes to increased neuronal activity in the posterior thalamic nucleus and associated chronic hyperesthesia after rat spinal cord contusion. Neurotherapeutics. 2013;10(3):520-38.

139. Gerke MB, Duggan AW, Xu L, Siddall PJ. Thalamic neuronal activity in rats with mechanical allodynia following contusive spinal cord injury. Neuroscience. 2003;117(3):715-22.

140. Hains BC, Saab CY, Waxman SG. Changes in electrophysiological properties and sodium channel Nav1.3 expression in thalamic neurons after spinal cord injury. Brain. 2005;128(Pt 10):2359-71.

141. Liang L, Mendell LM. Bilateral transient changes in thalamic nucleus ventroposterior lateralis after thoracic hemisection in the rat. J Neurophysiol. 2013;110(4):942-51.

142. Masri R, Quiton RL, Lucas JM, et al. Zona incerta: a role in central pain. J Neurophysiol. 2009;102(1):181-91.

143. Zhao P, Waxman SG, Hains BC. Modulation of thalamic nociceptive processing after spinal cord injury through remote activation of thalamic microglia by cysteine cysteine chemokine ligand 21 . J Neurosci. 2007;27(33):8893-902.

144. Hains BC, Saab CY, Waxman SG. Alterations in burst firing of thalamic VPL neurons and reversal by $\mathrm{Na}(\mathrm{v}) 1.3$ antisense after spinal cord injury. J Neurophysiol. 2006;95(6):3343-52.

145. Widerstrom-Noga E, Felix ER, Adcock JP, Escalona M, Tibbett J. Multidimensional neuropathic pain phenotypes after spinal cord injury. J Neurotrauma. 2016;33(5):482-92.

146. Soler MD, Morina D, Rodriguez N, et al. Sensory symptom profiles of patients with neuropathic pain after spinal cord injury. Clin J Pain. 2017;33(9):827-34.

147. Fields HL, Rowbotham M, Baron R. Postherpetic neuralgia: irritable nociceptors and deafferentation. Neurobiol Dis. 1998;5(4): 209-27.

148. Wasner G, Lee BB, Engel S, McLachlan E. Residual spinothalamic tract pathways predict development of central pain after spinal cord injury. Brain. 2008;131(Pt 9):2387-400.

149. Finnerup NB, Gyldensted C, Fuglsang-Frederiksen A, Bach FW, Jensen TS. Sensory perception in complete spinal cord injury. Acta Neurol Scand. 2004;109(3):194-9.

150. Huang CW, Huang CC, Lin MW, Tsai JJ, Wu SN. The synergistic inhibitory actions of oxcarbazepine on voltage-gated sodium and potassium currents in differentiated NG108-15 neuronal cells and model neurons. Int J Neuropsychopharmacol. 2008;11(5): 597-610.

151. Min K, Oh Y, Lee SH, Ryu JS. Symptom-based treatment of neuropathic pain in spinal cord-injured patients: a randomized crossover clinical trial. Am J Phys Med Rehabil. 2016;95(5): 330-8.

152. Westermann A, Krumova EK, Pennekamp W, et al. Different underlying pain mechanisms despite identical pain characteristics: a case report of a patient with spinal cord injury. Pain. 2012;153(7): 1537-40.

153. Holbech JV, Bach FW, Finnerup NB, Jensen TS, Sindrup SH. Pain phenotype as a predictor for drug response in painful polyneuropathy-a retrospective analysis of data from controlled clinical trials. Pain. 2016;157(6):1305-13.

154. Siddall P. Mechanisms-based assessment and treatment of pain: the art of fine dissection. Pain. 2012;153(7):1348-9.

155. Eide PK, Jorum E, Stenehjem AE. Somatosensory findings in patients with spinal cord injury and central dysaesthesia pain. J Neurol Neurosurg Psychiatry. 1996;60(4):411-5.

156. Finnerup NB, Johannesen IL, Bach FW, Jensen TS. Sensory function above lesion level in spinal cord injury patients with and without pain. Somatosens Mot Res. 2003;20(1):71-6.
157. Finnerup NB, Sorensen L, Biering-Sorensen F, Johannesen IL, Jensen TS. Segmental hypersensitivity and spinothalamic function in spinal cord injury pain. Exp Neurol. 2007;207(1):139-49.

158. Levitan Y, Zeilig G, Bondi M, Ringler E, Defrin R. Predicting the risk for central pain using the sensory components of the international standards for neurological classification of spinal cord injury. J Neurotrauma. 2015;32(21):1684-92.

159. Albu S, Gomez-Soriano J, Avila-Martin G, Taylor J. Deficient conditioned pain modulation after spinal cord injury correlates with clinical spontaneous pain measures. Pain. 2015;156(2): 260-72.

160. Gruener H, Zeilig G, Laufer Y, Blumen N, Defrin R. Differential pain modulation properties in central neuropathic pain after spinal cord injury. Pain. 2016;157(7):1415-24.

161. Finnerup NB, Sindrup SH, Bach FW, Johannesen IL, Jensen TS. Lamotrigine in spinal cord injury pain: a randomized controlled trial. Pain. 2002;96(3):375-83.

162. Skold C, Levi R, Seiger A. Spasticity after traumatic spinal cord injury: nature, severity, and location. Arch Phys Med Rehabil. 1999;80(12):1548-57.

163. Dimitrijevic MR, Nathan PW. Studies of spasticity in man. 4. Changes in flexion reflex with repetitive cutaneous stimulation in spinal man. Brain. 1970;93(4):743-68.

164. Fleuren JF, Voerman GE, Snoek GJ, et al. Perception of lower limb spasticity in patients with spinal cord injury. Spinal Cord. 2009;47(5):396-400.

165. Biering-Sorensen F, Burns AS, Curt A, et al. International spinal cord injury musculoskeletal basic data set. Spinal Cord. 2012;50(11):797-802.

166. Pandyan AD, Gregoric M, Barnes MP, et al. Spasticity: clinical perceptions, neurological realities and meaningful measurement. Disabil Rehabil. 2005;27(1-2):2-6.

167. Andresen SR, Biering-Sorensen F, Hagen EM, et al. Pain, spasticity and quality of life in individuals with traumatic spinal cord injury in Denmark. Spinal Cord. 2016;54(11):973-9.

168. Hagen EM, Rekand T. Management of neuropathic pain associated with spinal cord injury. Pain Ther. 2015;4(1):51-65.

169. Gruenthal M, Mueller M, Olson WL, et al. Gabapentin for the treatment of spasticity in patients with spinal cord injury. Spinal Cord. 1997;35(10):686-9.

170. Cote MP, Gandhi S, Zambrotta M, Houle JD. Exercise modulates chloride homeostasis after spinal cord injury. J Neurosci. 2014;34(27):8976-87.

171. Tashiro S, Shinozaki M, Mukaino M, et al. BDNF induced by treadmill training contributes to the suppression of spasticity and allodynia after spinal cord injury via upregulation of KCC2. Neurorehabil Neural Repair. 2015;29(7):677-89.

172. Dugan EA, Sagen J. An intensive locomotor training paradigm improves neuropathic pain following spinal cord compression injury in rats. J Neurotrauma. 2015;32(9):622-32.

173. Nees TA, Tappe-Theodor A, Sliwinski C, et al. Early-onset treadmill training reduces mechanical allodynia and modulates calcitonin gene-related peptide fiber density in lamina III/IV in a mouse model of spinal cord contusion injury. Pain. 2016;157(3):687-97.

174. Cardenas DD, Warms CA, Turner JA, et al. Efficacy of amitriptyline for relief of pain in spinal cord injury: results of a randomized controlled trial. Pain. 2002;96(3):365-73.

175. Loubser PG, Akman NM. Effects of intrathecal baclofen on chronic spinal cord injury pain. J Pain Symptom Manage. 1996;12(4): 241-7.

176. Bespalov A, Mus L, Zvartau E. Preclinical models of muscle spasticity: valuable tools in the development of novel treatment for neurological diseases and conditions. Naunyn Schmiedebergs Arch Pharmacol. 2016;389(5):457-66.

177. Corleto JA, Bravo-Hernandez M, Kamizato K, et al. Thoracic 9 spinal transection-induced model of muscle spasticity in the rat: a 
systematic electrophysiological and histopathological characterization. PLoS One. 2015;10(12):e0144642.

178. Kakinohana O, Hefferan MP, Nakamura S, et al. Development of GABA-sensitive spasticity and rigidity in rats after transient spinal cord ischemia: a qualitative and quantitative electrophysiological and histopathological study. Neuroscience. 2006;141(3):1569-83.

179. Ishikawa K, Ott K, Porter RW, Stuart D. Low frequency depression of the $\mathrm{H}$ wave in normal and spinal man. Exp Neurol. 1966;15(1):140-56.

180. Lee-Kubli CA, Calcutt NA. Altered rate-dependent depression of the spinal H-reflex as an indicator of spinal disinhibition in models of neuropathic pain. Pain. 2014;155(2):250-60.

181. Marshall AG, Lee-Kubli C, Azmi S, et al. Spinal disinhibition in experimental and clinical painful diabetic neuropathy. Diabetes. 2017;66(5):1380-90.

182. Kaila K, Price TJ, Payne JA, Puskarjov M, Voipio J. Cationchloride cotransporters in neuronal development, plasticity and disease. Nat Rev Neurosci. 2014;15(10):637-54.

183. Coull JA, Beggs S, Boudreau D, et al. BDNF from microglia causes the shift in neuronal anion gradient underlying neuropathic pain. Nature. 2005;438(7070):1017-21.

184. Nakamura M, Bregman BS. Differences in neurotrophic factor gene expression profiles between neonate and adult rat spinal cord after injury. Exp Neurol. 2001;169(2):407-15.

185. Li XL, Zhang W, Zhou X, et al. Temporal changes in the expression of some neurotrophins in spinal cord transected adult rats. Neuropeptides. 2007;41(3):135-43.

186. Asiedu MN, Mejia GL, Hubner CA, Kaila K, Price TJ. Inhibition of carbonic anhydrase augments GABAA receptor-mediated analgesia via a spinal mechanism of action. J Pain. 2014;15(4): 395-406.

187. Cairns DM, Adkins RH, Scott MD. Pain and depression in acute traumatic spinal cord injury: origins of chronic problematic pain? Arch Phys Med Rehabil. 1996;77(4):329-35.

188. Hoffman JM, Bombardier CH, Graves DE, Kalpakjian CZ, Krause JS. A longitudinal study of depression from 1 to 5 years after spinal cord injury. Arch Phys Med Rehabil. 2011;92(3):411-8.

189. Hartoonian N, Hoffman JM, Kalpakjian CZ, et al. Evaluating a spinal cord injury-specific model of depression and quality of life. Arch Phys Med Rehabil. 2014;95(3):455-65.

190. Norrbrink Budh C, Hultling C, Lundeberg T. Quality of sleep in individuals with spinal cord injury: a comparison between patients with and without pain. Spinal Cord. 2005;43(2):85-95.

191. Craig AR, Hancock KM, Dickson HG. Spinal cord injury: a search for determinants of depression two years after the event. Br J Clin Psychol. 1994;33 ( Pt 2):221-30.

192. Cuff L, Fann JR, Bombardier CH, Graves DE, Kalpakjian CZ. Depression, pain intensity, and interference in acute spinal cord injury. Top Spinal Cord Inj Rehabil. 2014;20(1):32-9.

193. Nicholson Perry K, Nicholas MK, Middleton J, Siddall P. Psychological characteristics of people with spinal cord injuryrelated persisting pain referred to a tertiary pain management center. J Rehabil Res Dev. 2009;46(1):57-67.

194. Craig A, Tran Y, Middleton J. Psychological morbidity and spinal cord injury: a systematic review. Spinal Cord. 2009;47(2):108-14.

195. Kennedy P, Rogers BA. Anxiety and depression after spinal cord injury: a longitudinal analysis. Arch Phys Med Rehabil. 2000;81(7):932-7.

196. Wollaars MM, Post MW, van Asbeck FW, Brand N. Spinal cord injury pain: the influence of psychologic factors and impact on quality of life. Clin J Pain. 2007;23(5):383-91.

197. Lees JG, Fivelman B, Duffy SS, et al. Cytokines in neuropathic pain and associated depression. Mod Trends Pharmacopsychiatry. 2015;30:51-66
198. Howren MB, Lamkin DM, Suls J. Associations of depression with C-reactive protein, IL-1, and IL-6: a meta-analysis. Psychosom Med. 2009;71(2):171-86.

199. Dowlati Y, Herrmann N, Swardfager W, et al. A meta-analysis of cytokines in major depression. Biol Psychiatry. 2010;67(5): 446-57.

200. Liu Y, Ho RC, Mak A. The role of interleukin (IL)-17 in anxiety and depression of patients with rheumatoid arthritis. Int $\mathrm{J}$ Rheum Dis. 2012;15(2):183-7.

201. Segal JL, Gonzales E, Yousefi S, Jamshidipour L, Brunnemann SR. Circulating levels of IL-2R, ICAM-1, and IL-6 in spinal cord injuries. Arch Phys Med Rehabil. 1997;78(1):44-7.

202. Hayes KC, Hull TC, Delaney GA, et al. Elevated serum titers of proinflammatory cytokines and CNS autoantibodies in patients with chronic spinal cord injury. J Neurotrauma. 2002;19(6):753-61.

203. Davies AL, Hayes KC, Dekaban GA. Clinical correlates of elevated serum concentrations of cytokines and autoantibodies in patients with spinal cord injury. Arch Phys Med Rehabil. 2007;88(11):1384-93.

204. Kwon BK, Stammers AM, Belanger LM, et al. Cerebrospinal fluid inflammatory cytokines and biomarkers of injury severity in acute human spinal cord injury. J Neurotrauma. 2010;27(4):669-82.

205. Allison DJ, Ditor DS. Targeting inflammation to influence mood following spinal cord injury: a randomized clinical trial. J Neuroinflammation. 2015;12:204.

206. Allison DJ, Thomas A, Beaudry K, Ditor DS. Targeting inflammation as a treatment modality for neuropathic pain in spinal cord injury: a randomized clinical trial. J Neuroinflammation. 2016;13(1):152.

207. Wu J, Zhao Z, Kumar A, et al. Endoplasmic reticulum stress and disrupted neurogenesis in the brain are associated with cognitive impairment and depressive-like behavior after spinal cord injury. J Neurotrauma. 2016;33(21):1919-35.

208. Wu J, Stoica BA, Luo T, et al. Isolated spinal cord contusion in rats induces chronic brain neuroinflammation, neurodegeneration, and cognitive impairment. Involvement of cell cycle activation. Cell Cycle. 2014;13(15):2446-58.

209. Wu J, Zhao Z, Sabirzhanov B, et al. Spinal cord injury causes brain inflammation associated with cognitive and affective changes: role of cell cycle pathways. J Neurosci. 2014;34(33): 10989-1006.

210. Wu J, Sabirzhanov B, Stoica BA, et al. Ablation of the transcription factors E2F1-2 limits neuroinflammation and associated neurological deficits after contusive spinal cord injury. Cell Cycle. 2015;14(23):3698-712.

211. Thompson C, Mutch J, Parent S, Mac-Thiong JM. The changing demographics of traumatic spinal cord injury: an 11-year study of 831 patients. J Spinal Cord Med. 2015;38(2):214-23.

212. Norrbrink Budh C, Lund I, Ertzgaard P, et al. Pain in a Swedish spinal cord injury population. Clin Rehabil. 2003;17(6):685-90.

213. Cardenas DD, Bryce TN, Shem K, Richards JS, Elhefni H. Gender and minority differences in the pain experience of people with spinal cord injury. Arch Phys Med Rehabil. 2004;85(11):1774-81.

214. Norrbrink Budh C, Lund I, Hultling C, et al. Gender related differences in pain in spinal cord injured individuals. Spinal Cord. 2003;41(2):122-8.

215. Bartley EJ, Fillingim RB. Sex differences in pain: a brief review of clinical and experimental findings. Br J Anaesth 2013;111(1):52-8.

216. Gaudet AD, Ayala MT, Schleicher WE, et al. Exploring acute-tochronic neuropathic pain in rats after contusion spinal cord injury. Exp Neurol. 2017;295:46-54

217. Acosta-Rua AJ, Cannon RL, Yezierski RP, Vierck CJ. Sex differences in effects of excitotoxic spinal injury on below-level pain sensitivity. Brain Res. 2011;1419:85-96. 
218. Gwak YS, Hains BC, Johnson KM, Hulsebosch CE. Effect of age at time of spinal cord injury on behavioral outcomes in rat. $\mathrm{J}$ Neurotrauma. 2004;21(8):983-93.

219. Gwak YS, Hains BC, Johnson KM, Hulsebosch CE. Locomotor recovery and mechanical hyperalgesia following spinal cord injury depend on age at time of injury in rat. Neurosci Lett. 2004;362(3): 232-5.

220. Yezierski RP. The effects of age on pain sensitivity: preclinical studies. Pain Med. 2012;13 Suppl 2:S27-36.
221. Hooshmand MJ, Galvan MD, Partida E, Anderson AJ. Characterization of recovery, repair, and inflammatory processes following contusion spinal cord injury in old female rats: is age a limitation? Immun Ageing. 2014;11:15.

222. Badner A, Siddiqui AM, Fehlings MG. Spinal cord injuries: how could cell therapy help? Expert Opin Biol Ther. 2017;17(5):529-41.

223. Alam M, Rodrigues W, Pham BN, Thakor NV. Brain-machine interface facilitated neurorehabilitation via spinal stimulation after spinal cord injury: Recent progress and future perspectives. Brain Res. 2016;1646:25-33. 